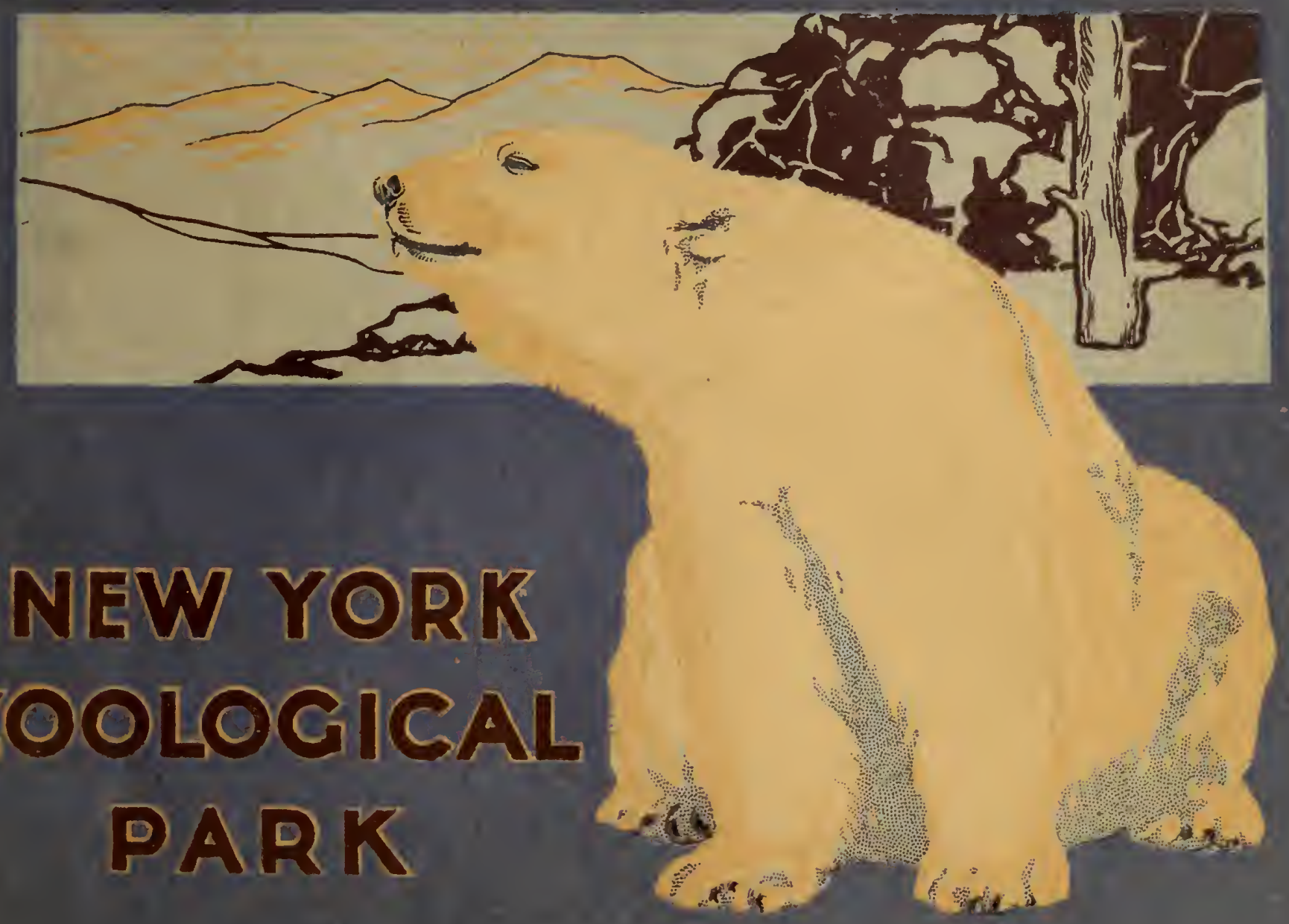


AVERY ARCHITECTLRAL AND FINE ARTS LIBRARY

GifT OF SEYMOUR B. DURST OLD York LibraRY 


\section{NEW YORK ZOOLOGICAL PARK BOOK OF VIEWS}

ILLUSTRATED BY

ELWIN R. SANBORN

Official Photographer

PUBLISHED BY

THE NEIW YORK

ZOOLOGICAL SOCIETY

NFW YORK, 1912

Copyright 1912, New York Zoologicai Society

SERIES NUMBER THREE

For duplicates of this book, information in regard to Souvenir Postal Cards, Guide Books or other Zoological Park publications, address: H. R. Mitchell, Mlanager of Privileges, Zoological Park. 185th Street and Southern Boulevard, New York City

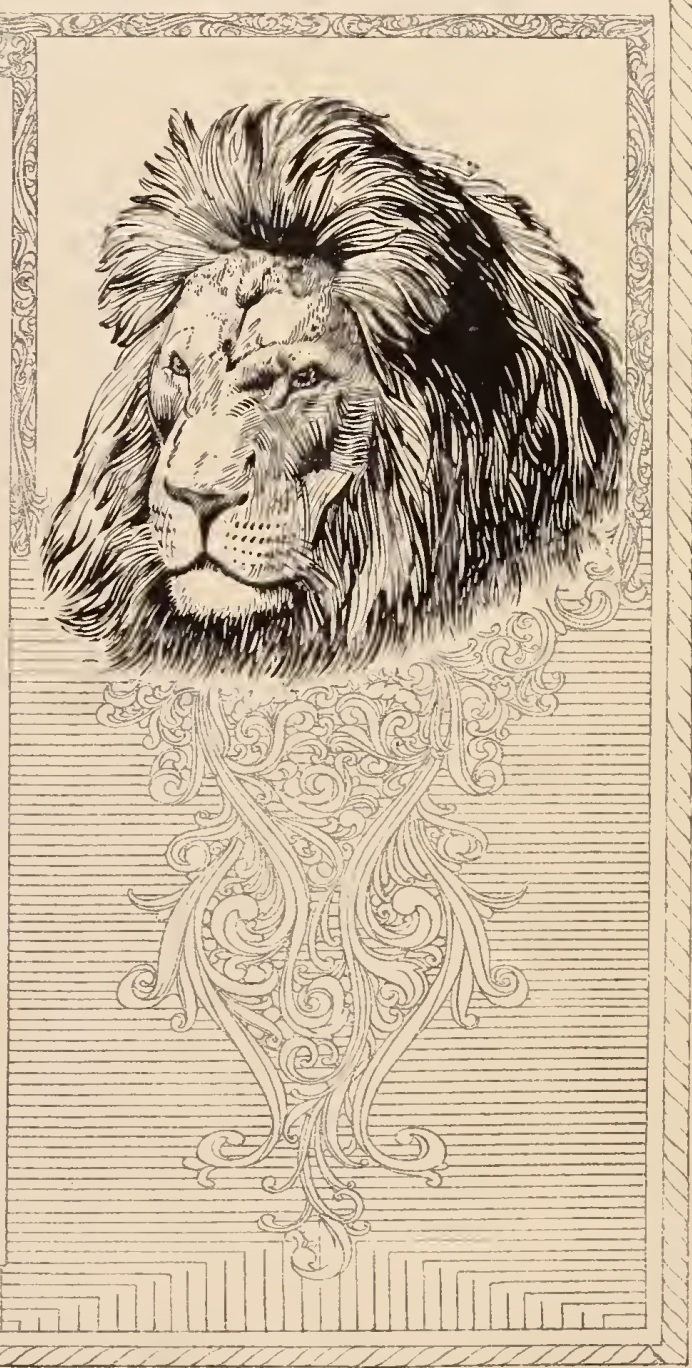




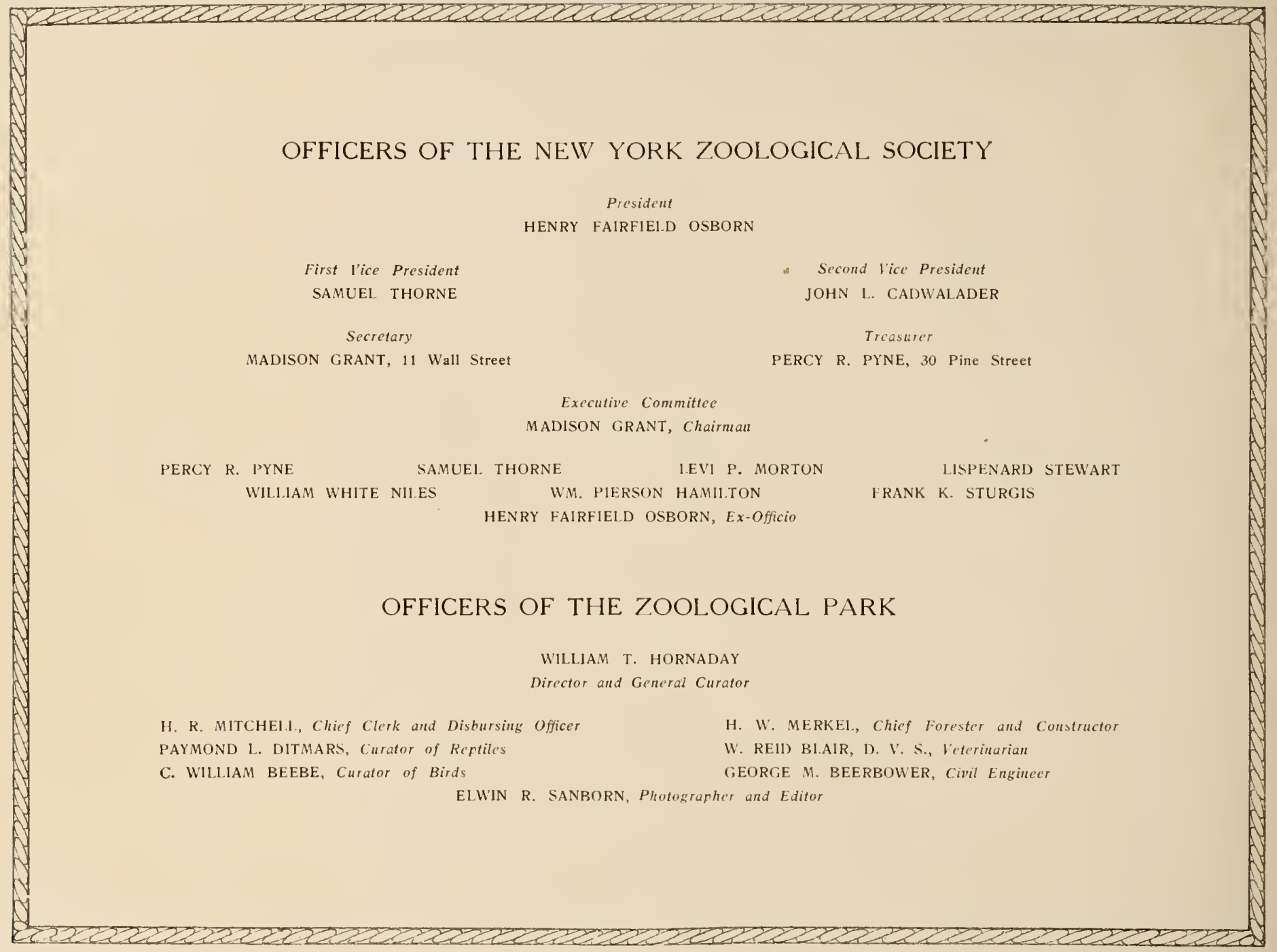




\section{NEW York ZoOlogical Park}

Under the Management of the New York Zoological Society

$\mathrm{T}$

HE rapid decrease of wild animal life throughout the world, and the inability of the millions to study wild animals

in their native haunts, have created a wide-spread demand for zoological gardens and parks. In the United
States nearly every large city either has an institution for the exhibition of living animals, or is preparing to establish one.

The New York Zoological Park originated in 1895 with the New York Zoological Society, a scientific corporation, having for its objects "a public Zoological Park, the preservation of our native animals and the promotion of zoology." The Society now consists of 1902 members of all classes, and is charged with the management of the Park.

Unlike most of the Zoological Gardens of Europe, the New York Zoological Park is free to the public on five days of each week. The pay days are Mondays and Thursdays, except that on all legal holidays admission is free. The grounds, many of the buildings, and an annual maintenance fund are provided by the city. The remainder of the buildings and the animal collections are furnished by the Society.

The area of the Park is nearly 300 acres - a magnificent domain to be thus dedicated to zoology and public instruction. It contains thirty-five acres of water, and its land consists of heavy forest, open forest, and meadow glades, in about equal proportions. The extreme length of the Park is 330 feet less than a mile, and its extreme width is about threefifths of a mile.

The principal buildings of the Park are the Elephant House, Lion House, Primate House, Zebra House, Large Bird House, Reptile House, Antelope, Ostrich and Small Mammal Houses, and the Aquatic Bird House. The principal open air enclosures are the Bear Dens. Flying Cage, Pheasant Aviary, and the Eagle and Vulture Aviary, Wolf and Fox Dens, Burrowing Rodent Quarters, Beaver Pond, Duck Aviary, Wild Fowl Pond, and Mountain Sheep Hill.

The most valuable and important collections in the Park are the lions, tigers, and leopards, the tropical hoofed animals in the Antelope House, the bears, the bison herd of thirly-seven animals and the apes and monkeys. The collection of Asiatic deer is second only to that of the Berlin Zoological Garden. The most interesting animals in the whole collection are the chimpanzees and orang-utans, in the Primate House, and the Pygmy Hippopotami. The collections of bears and of tropical antelopes are certainly equal to the largest and finest of their kinds to be found elsewhere, and the collection of reptiles is also unsurpassed. species.

The collection of living birds is now the largest in the world in actual number of specimens, and third in number of

The creation of a really great zoological garden or park requires a great many people, as well as a great many animals, and much money. The annual expenditures for animal;-all of which is furnished by the Zoological Society-are very considerable, and a large membership is vitally necessary to the existence of this institution. The Society invites to its membership all persons who are interested in the objects it is seeking to promote. 


\section{ANIMAL STATISTICS OF THE LARGEST ZOOLOGICAL GARDENS OF THE IVORLD}

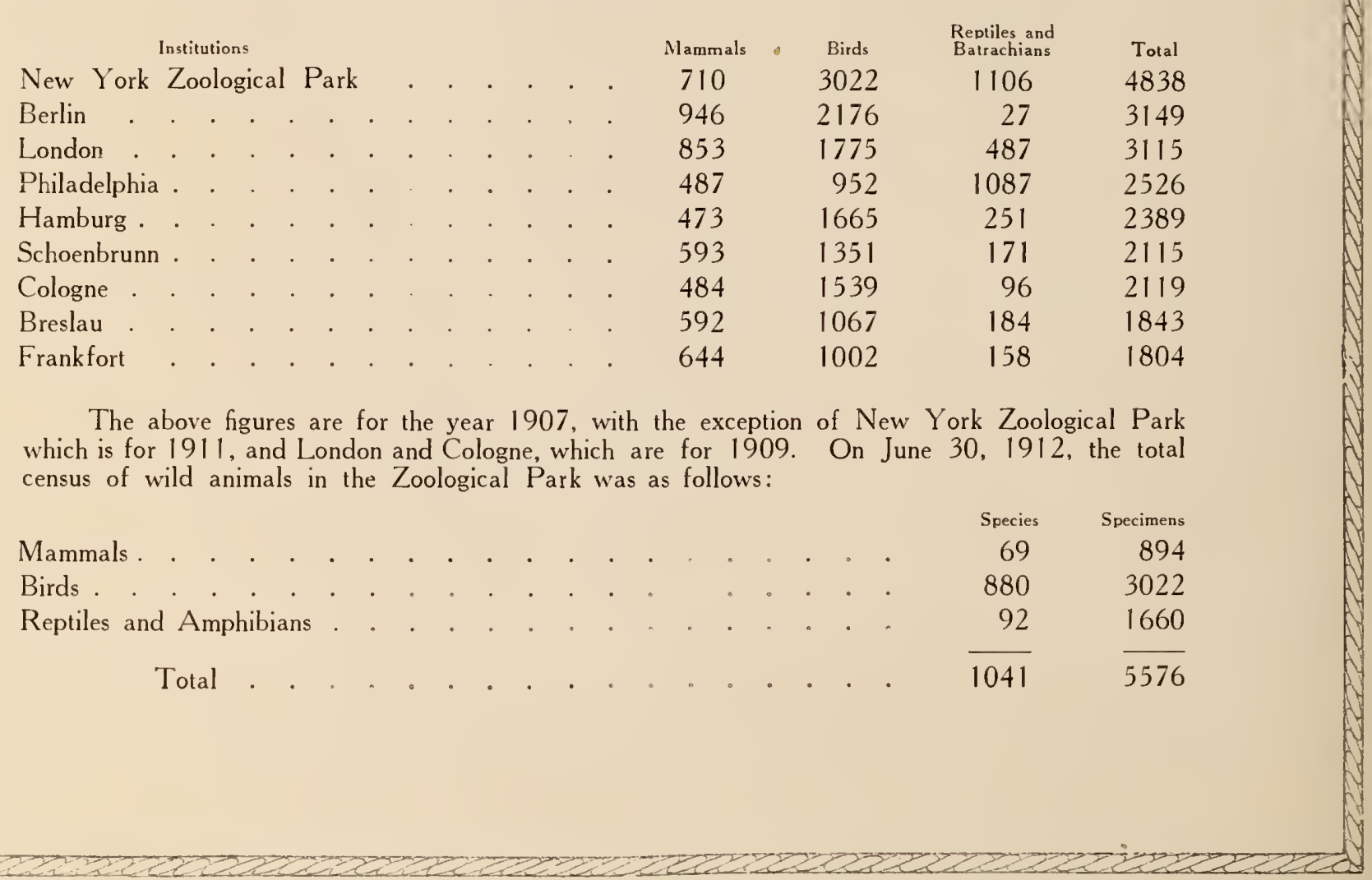




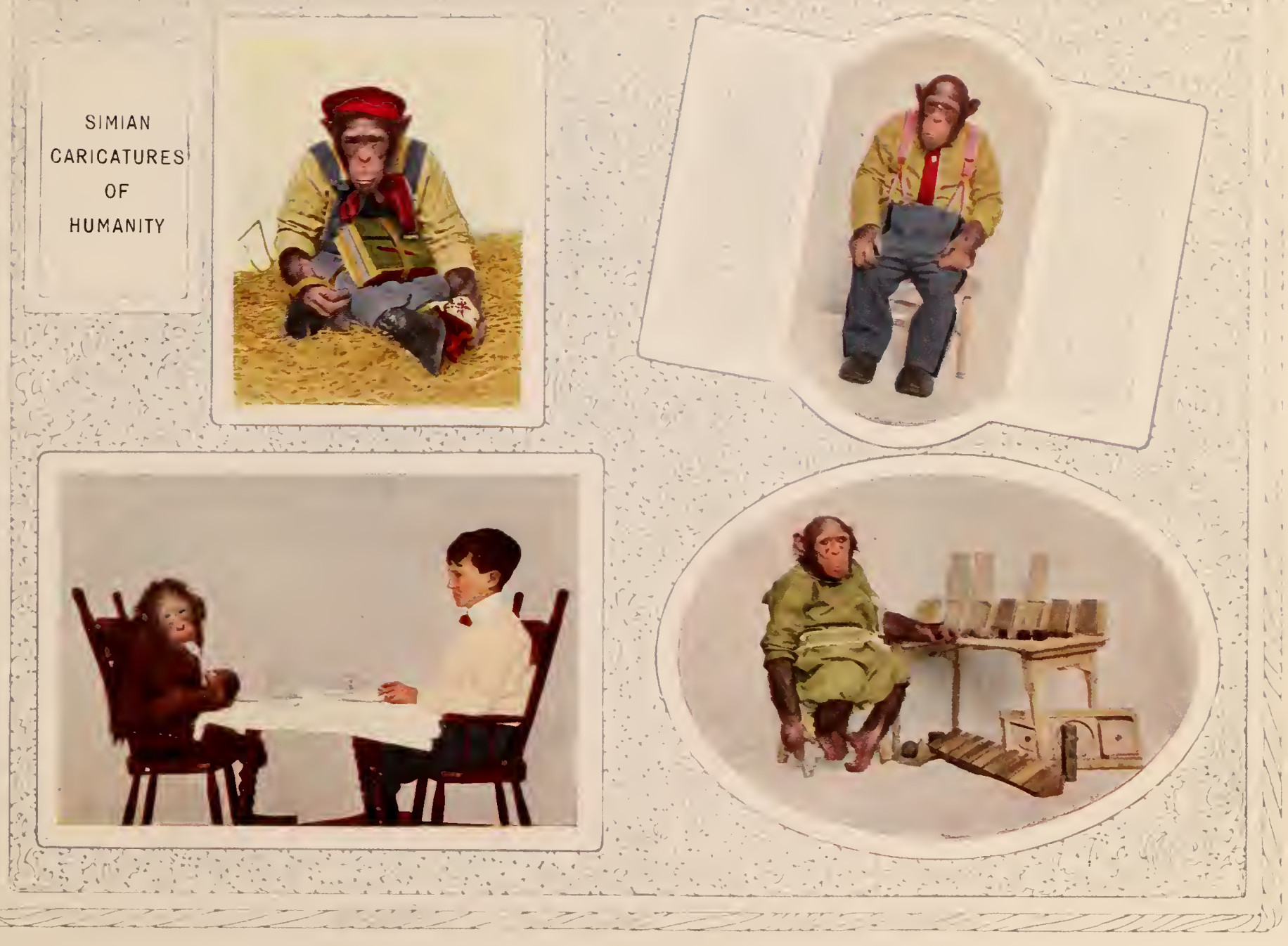



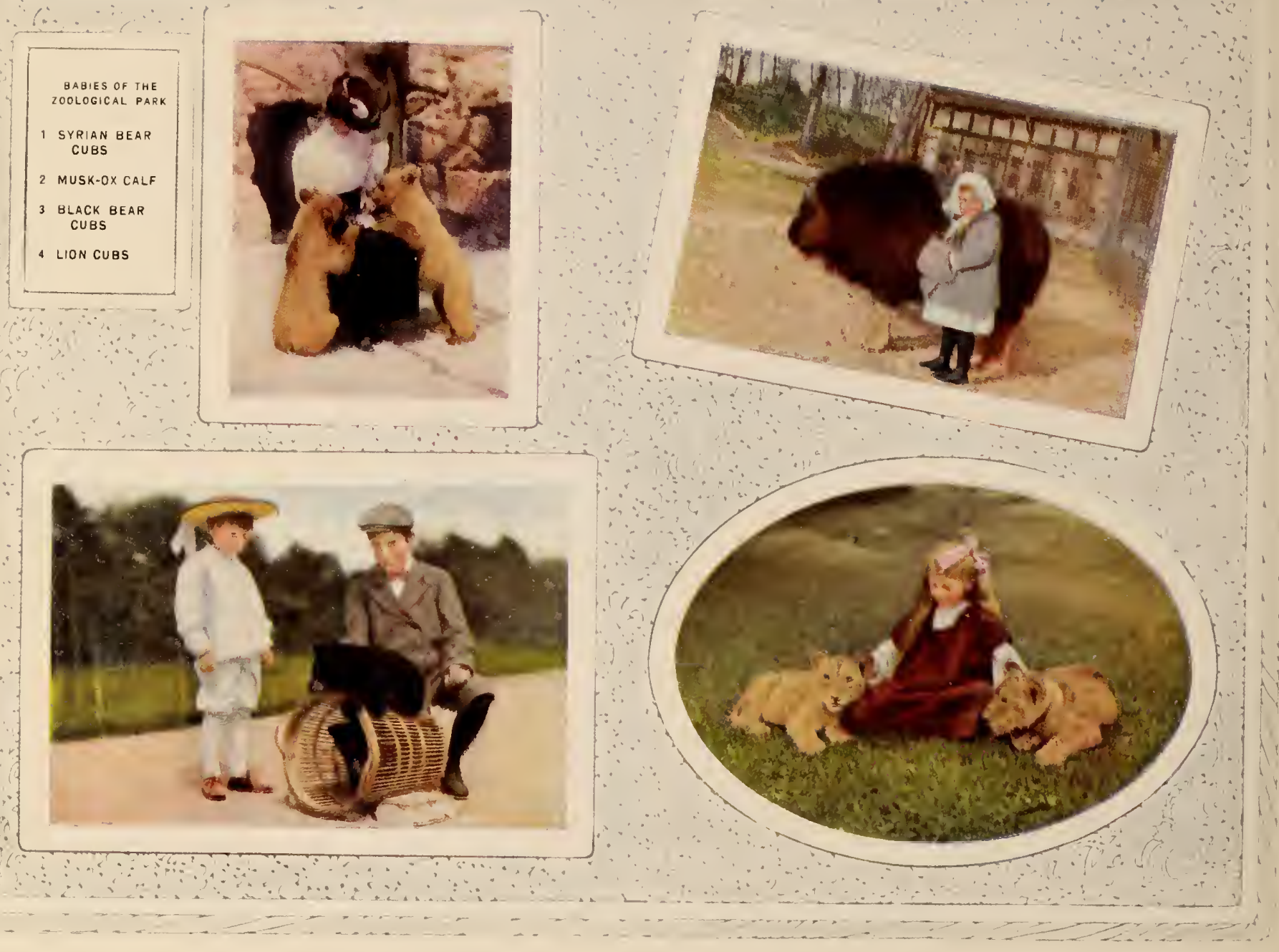


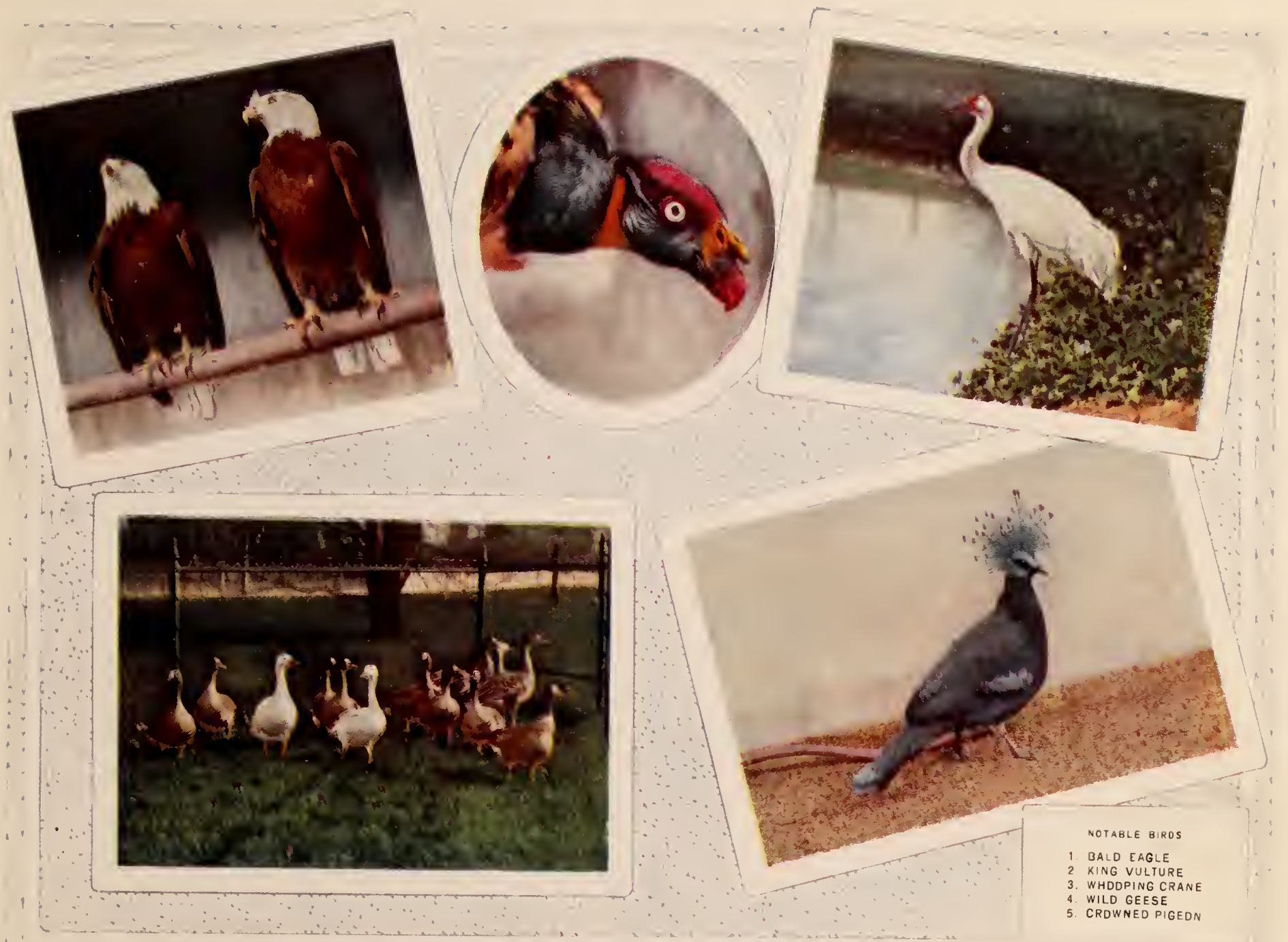




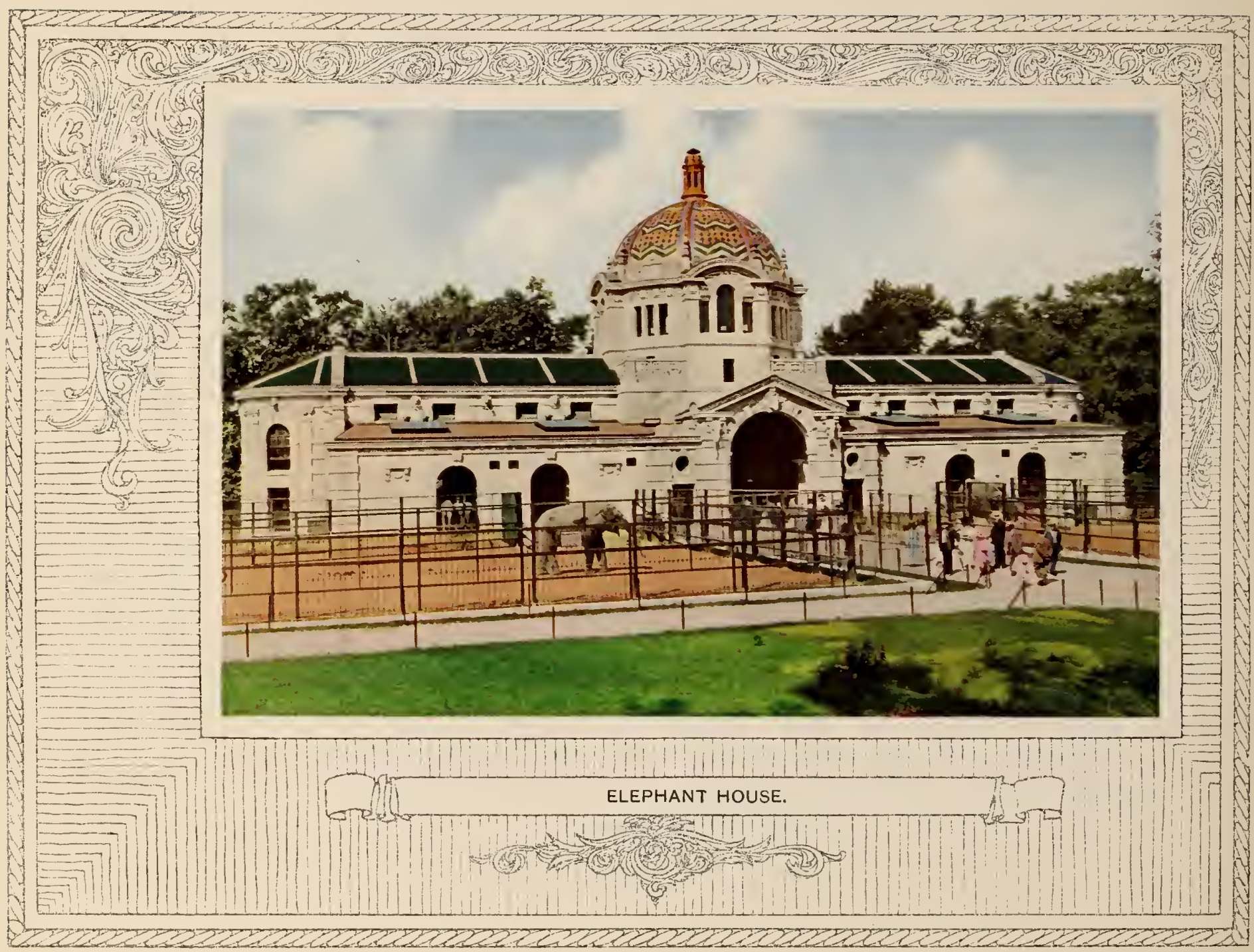




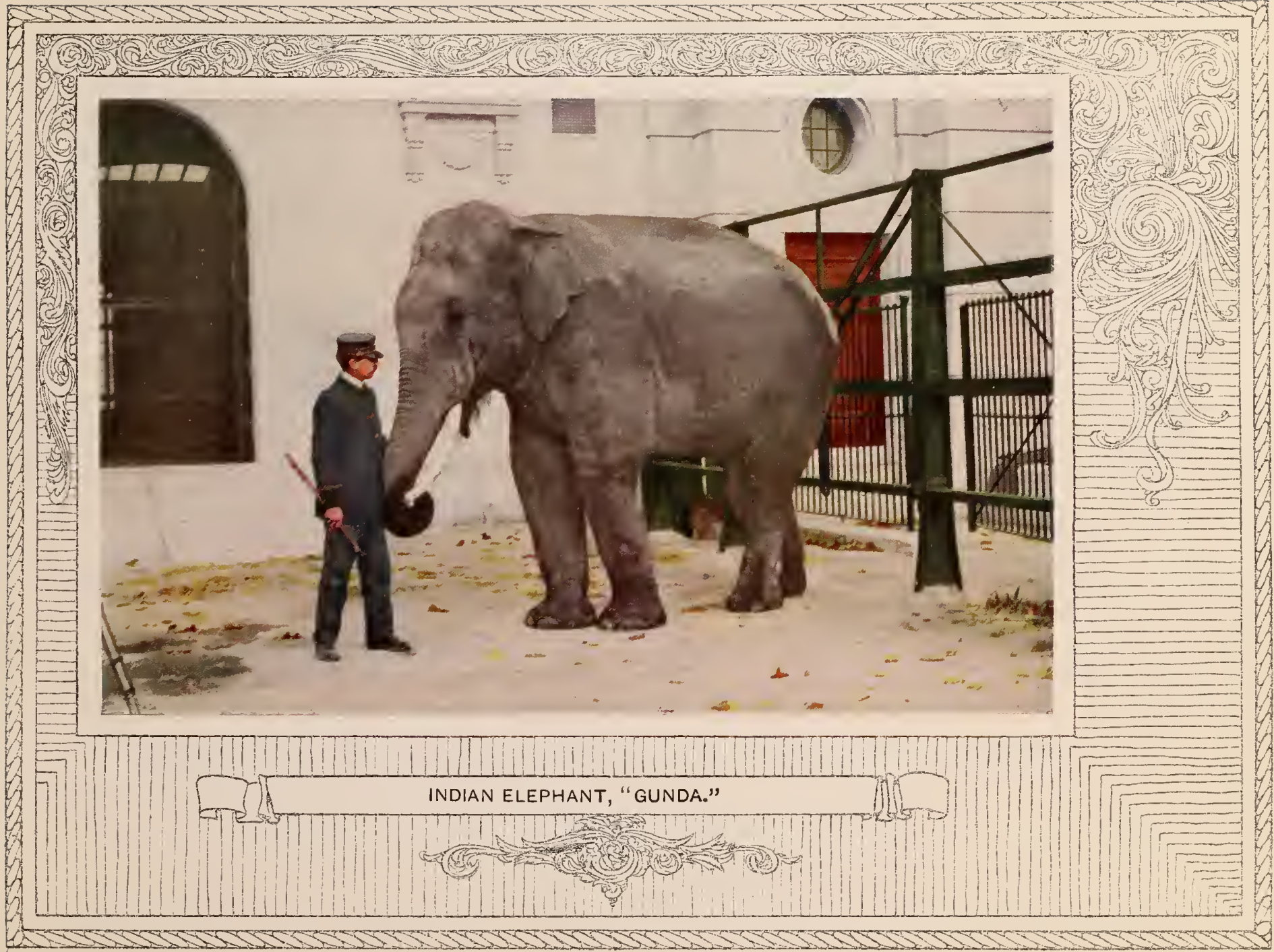




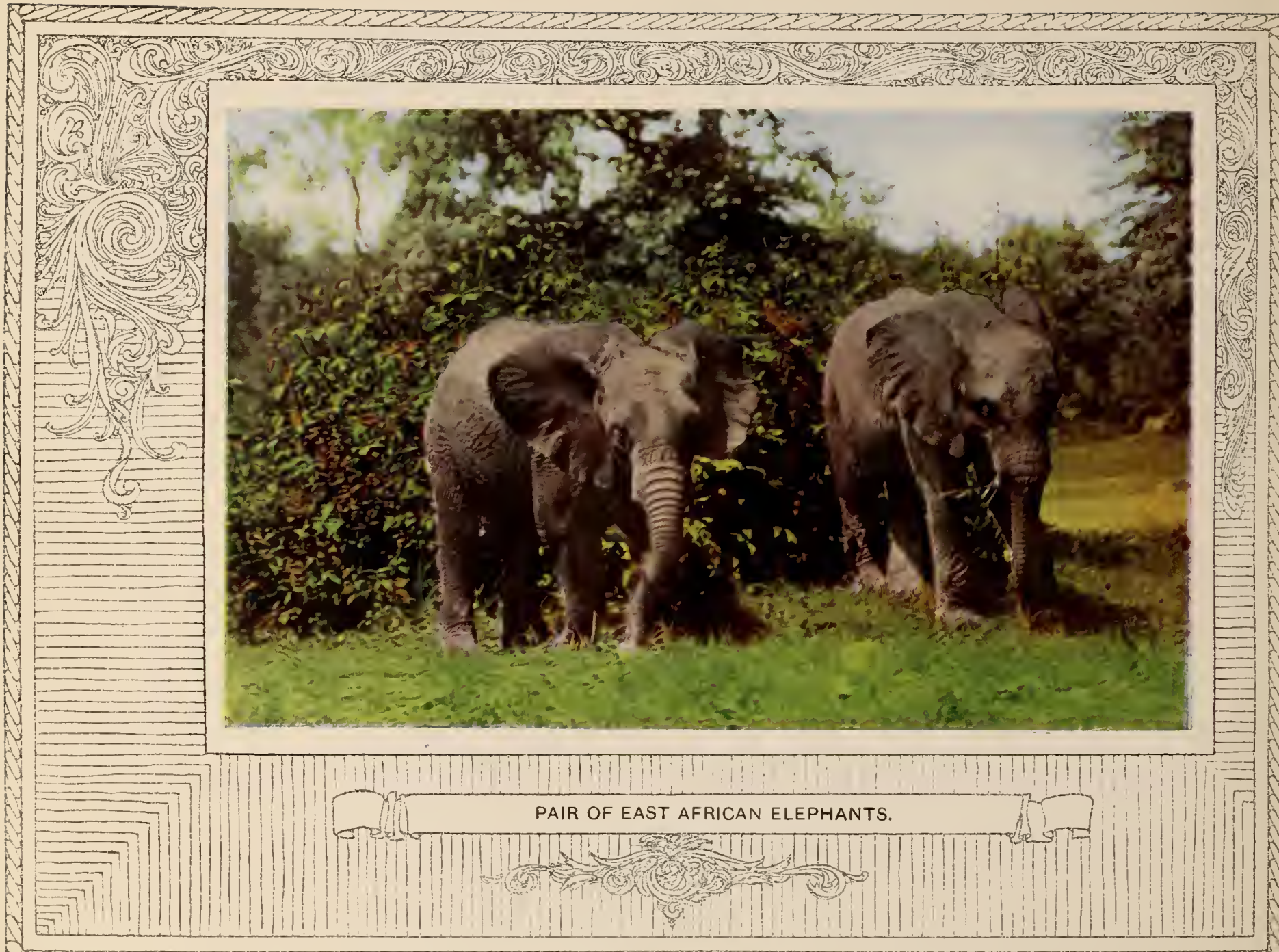

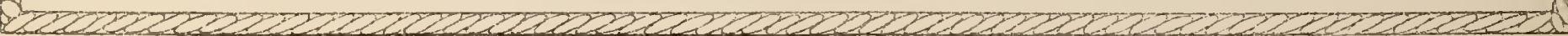




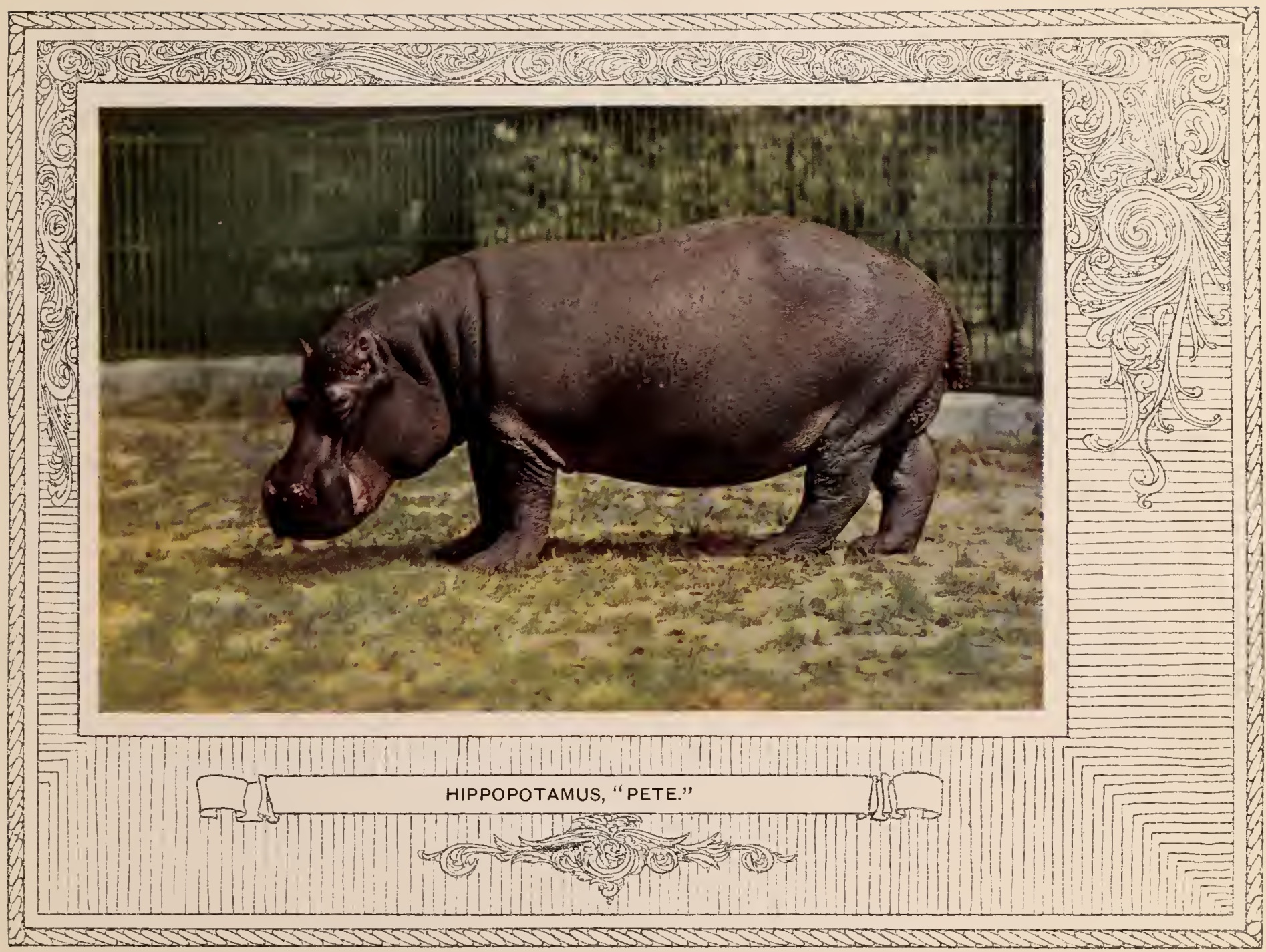




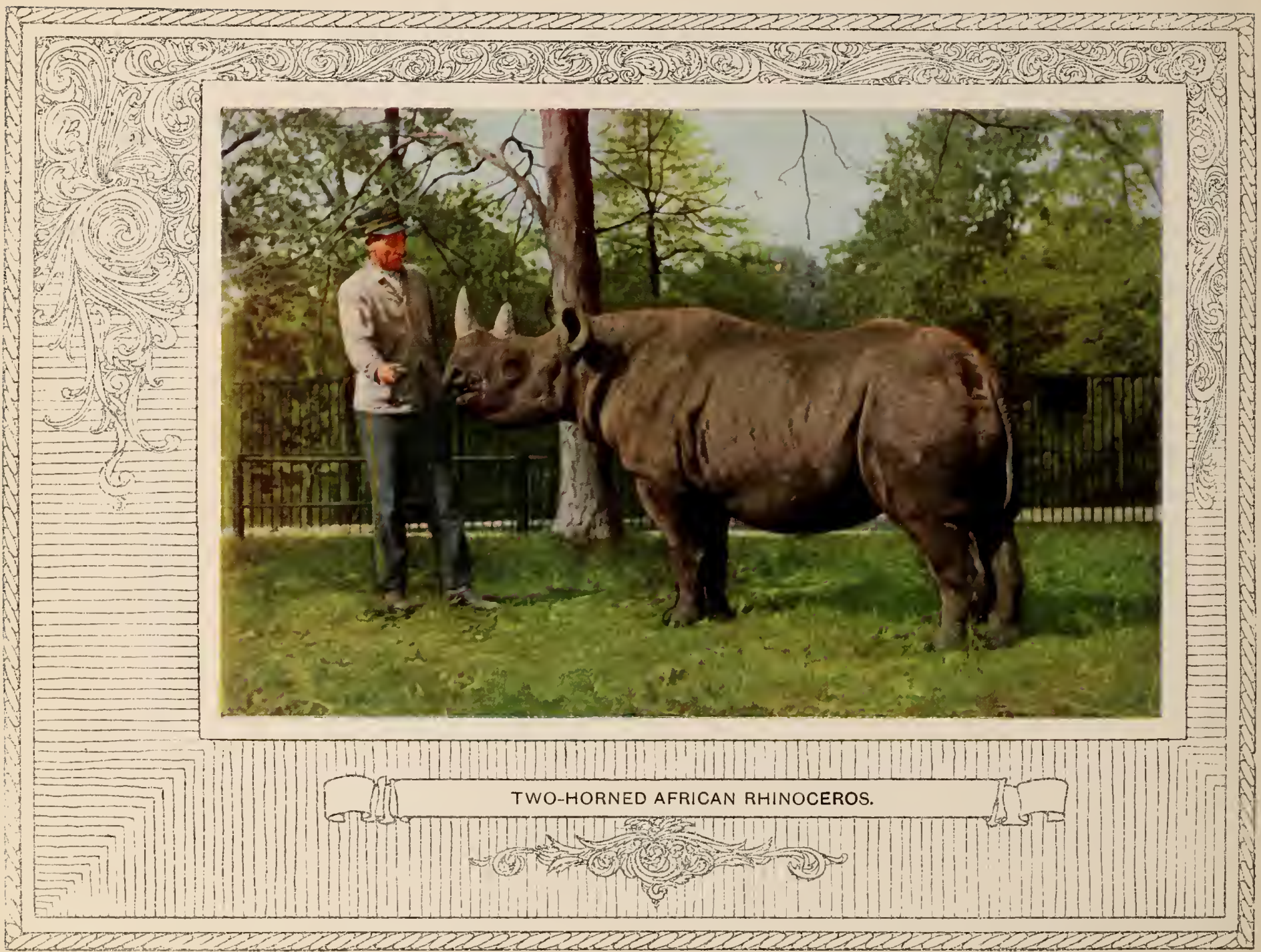




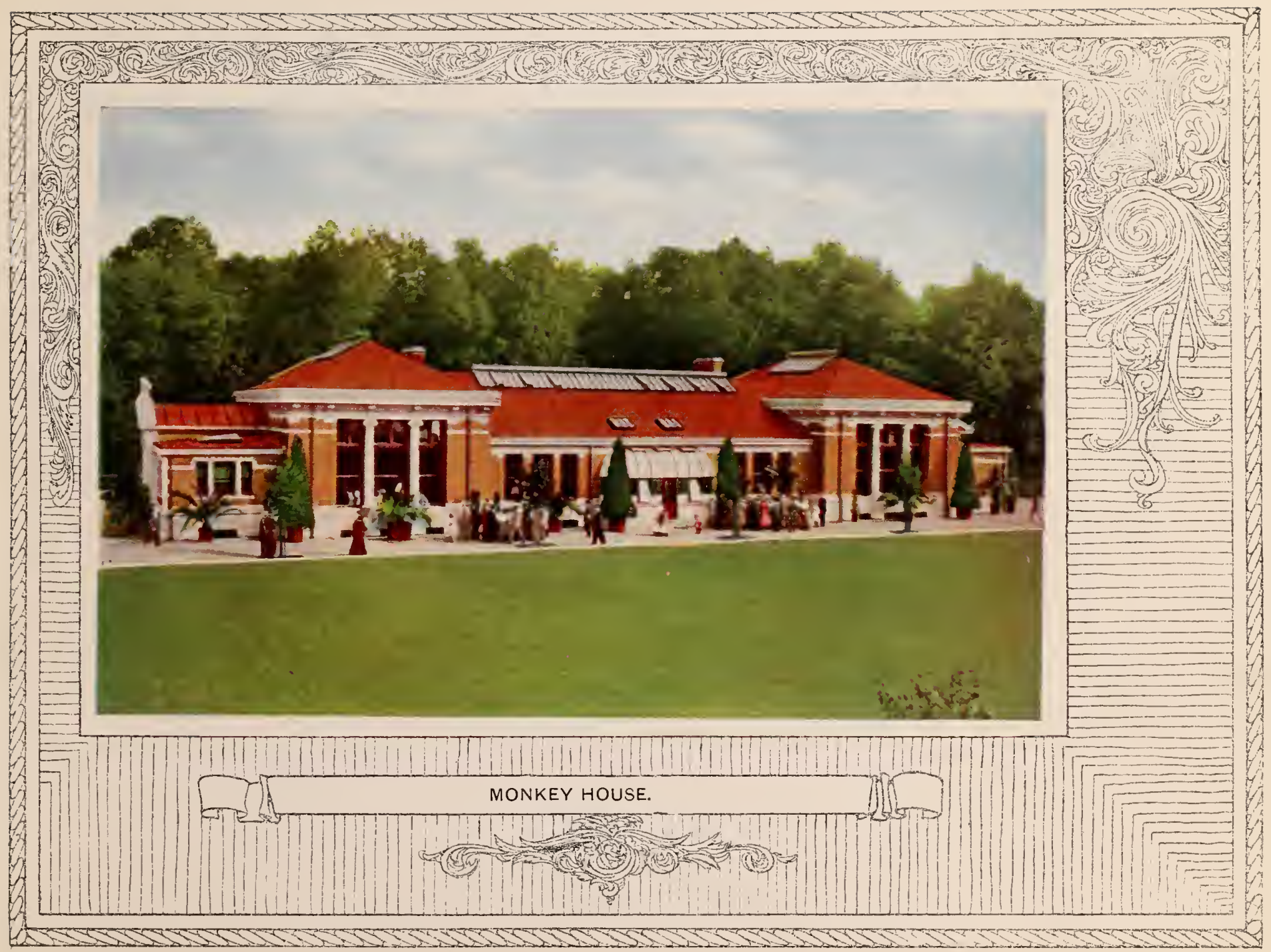




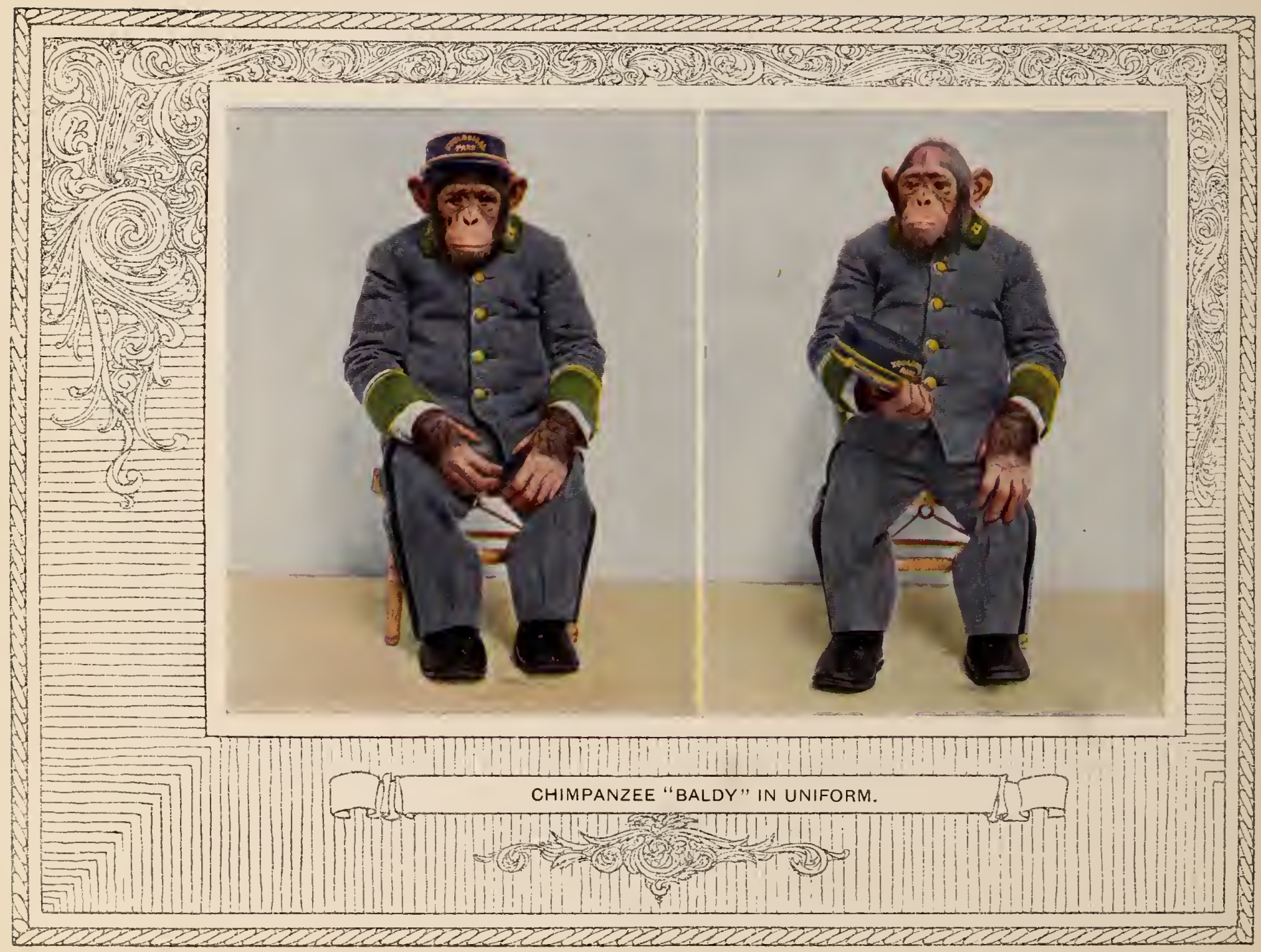




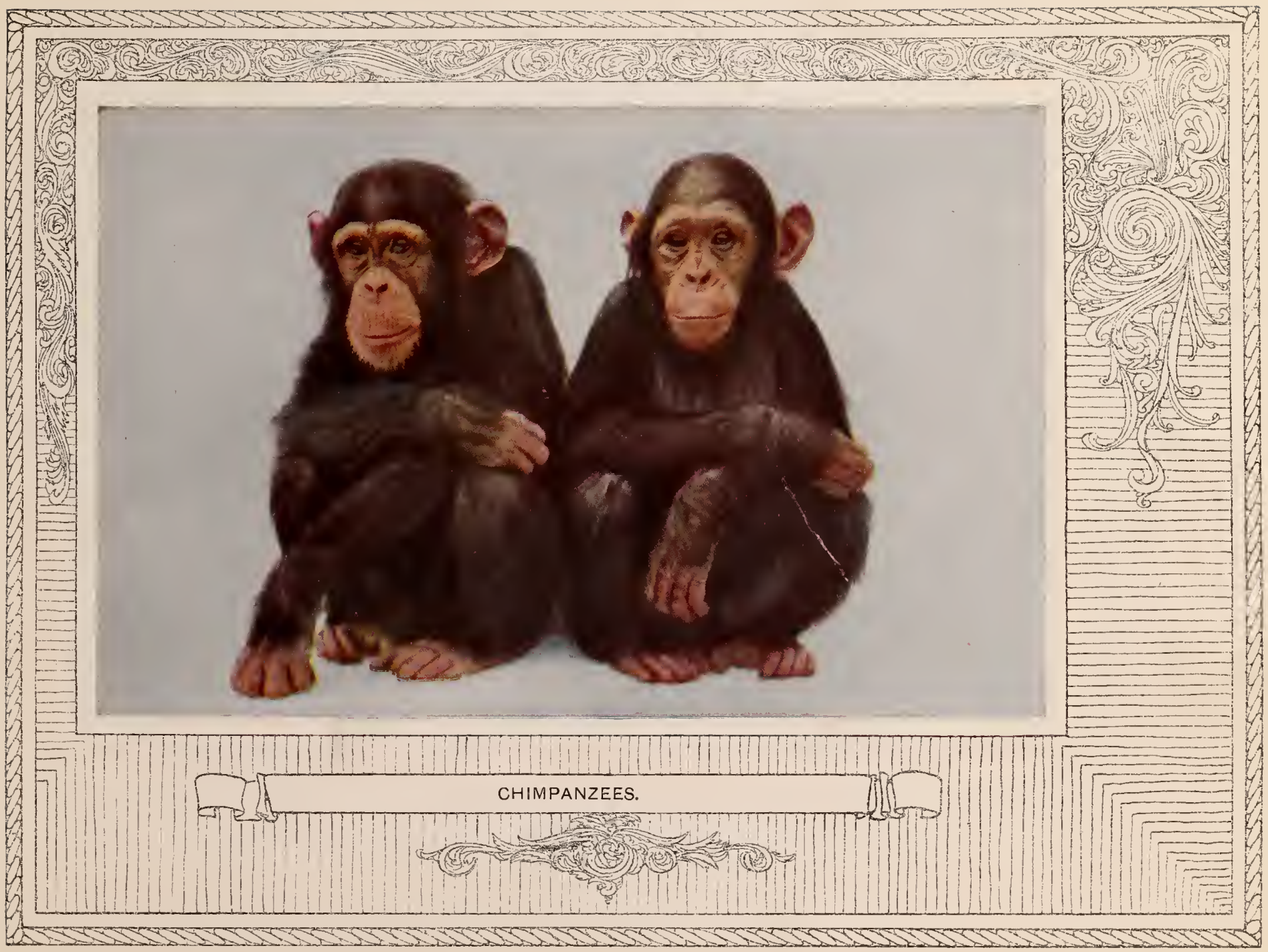




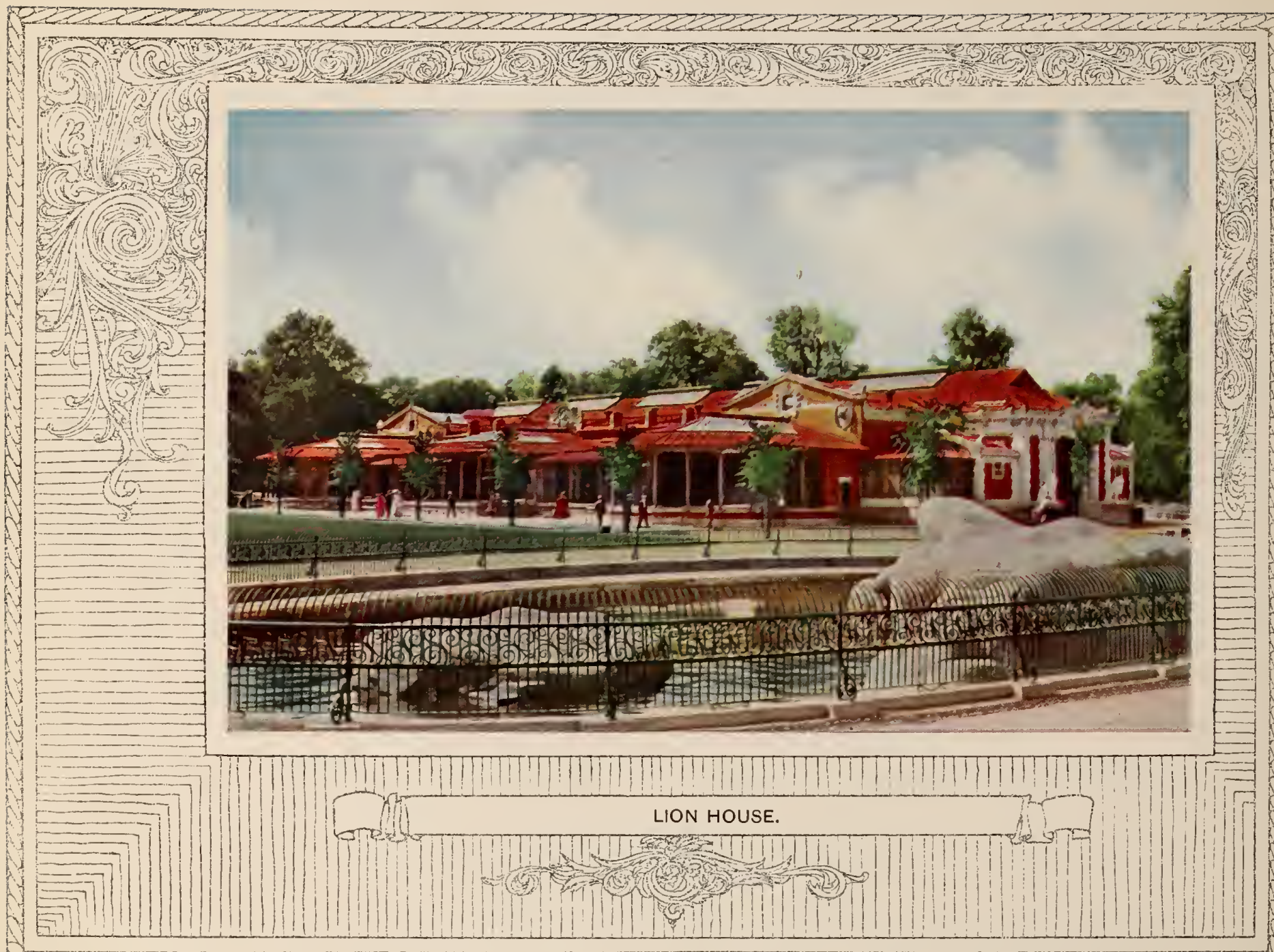

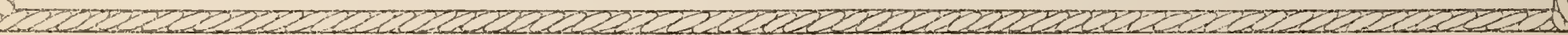




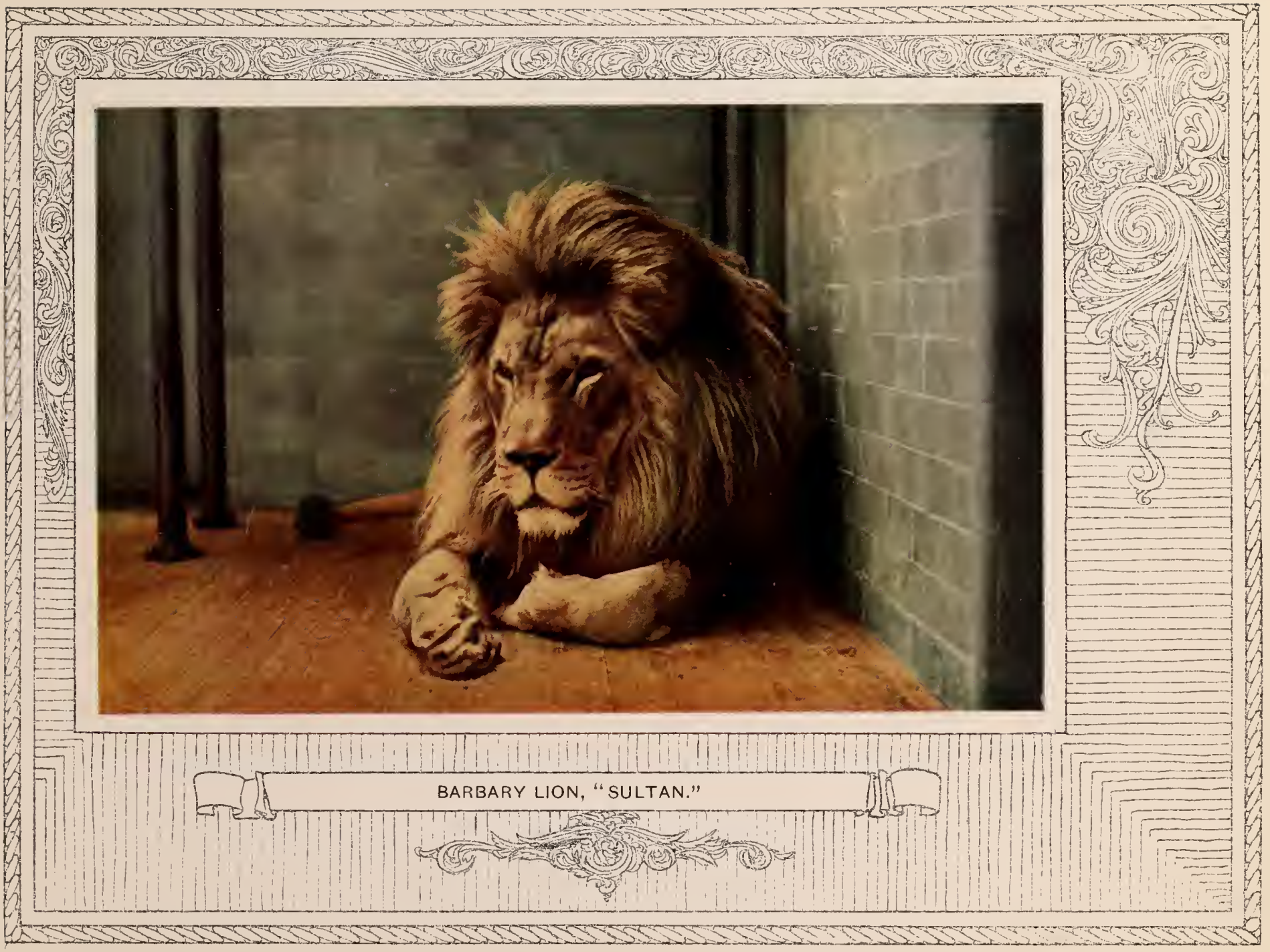




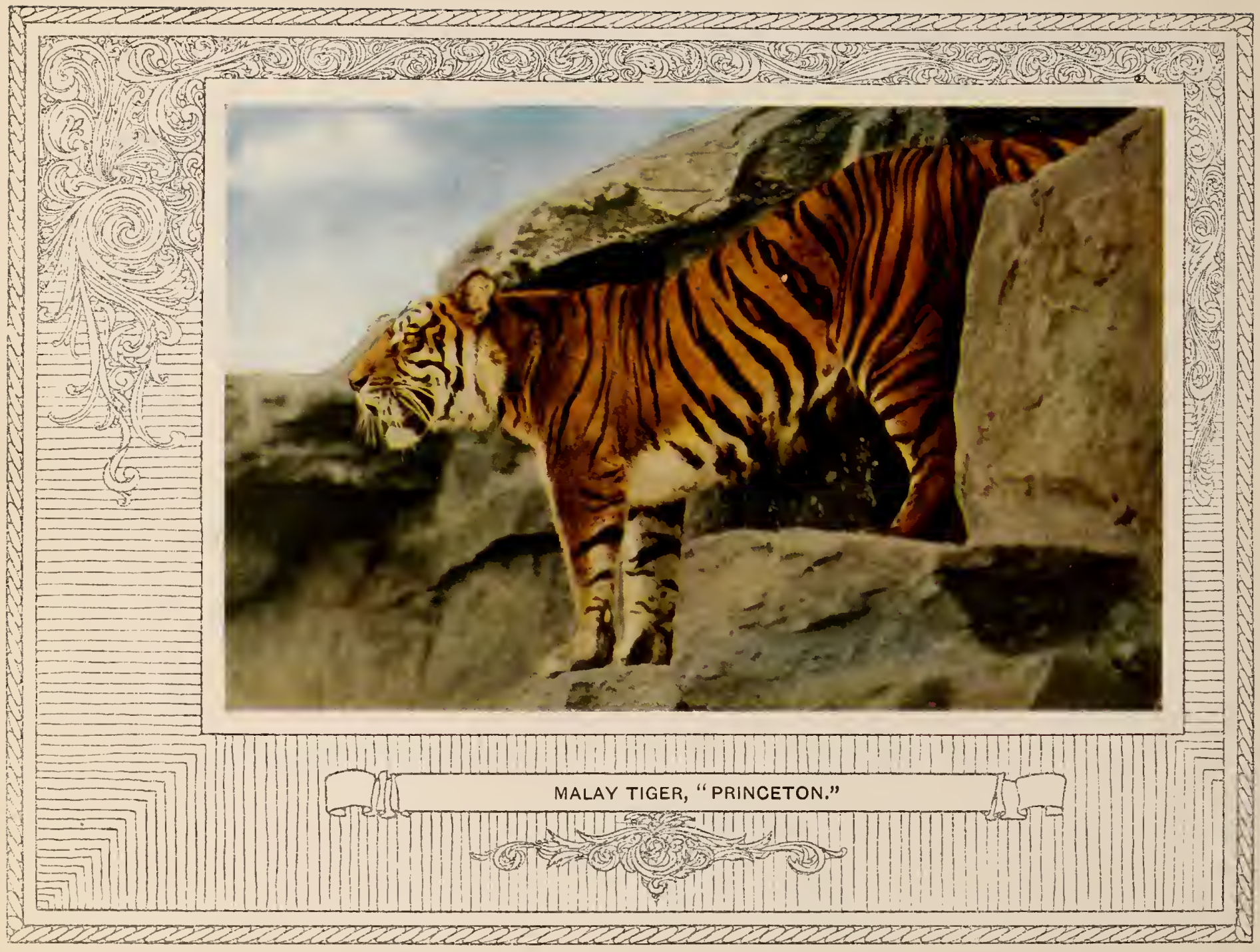




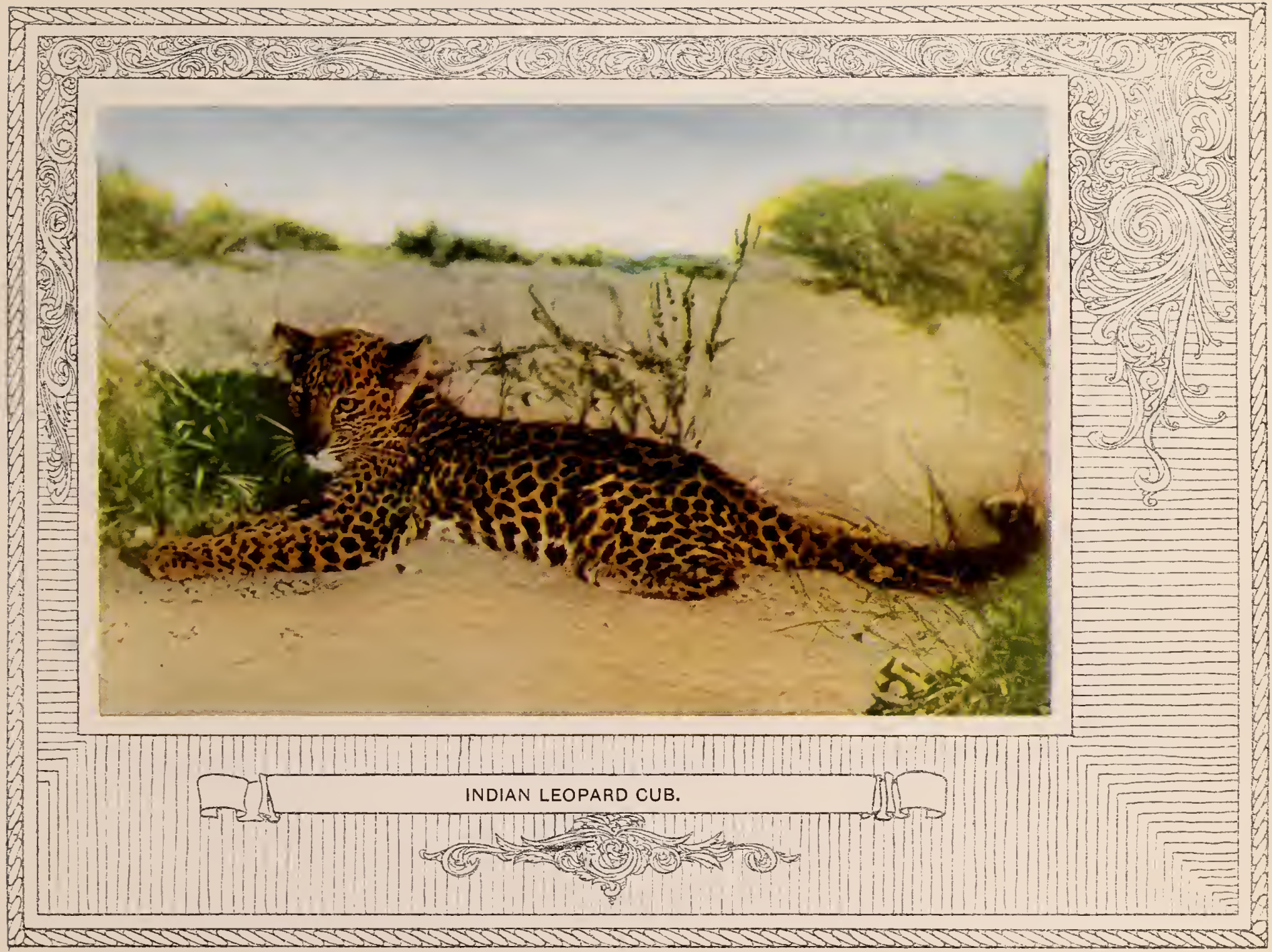




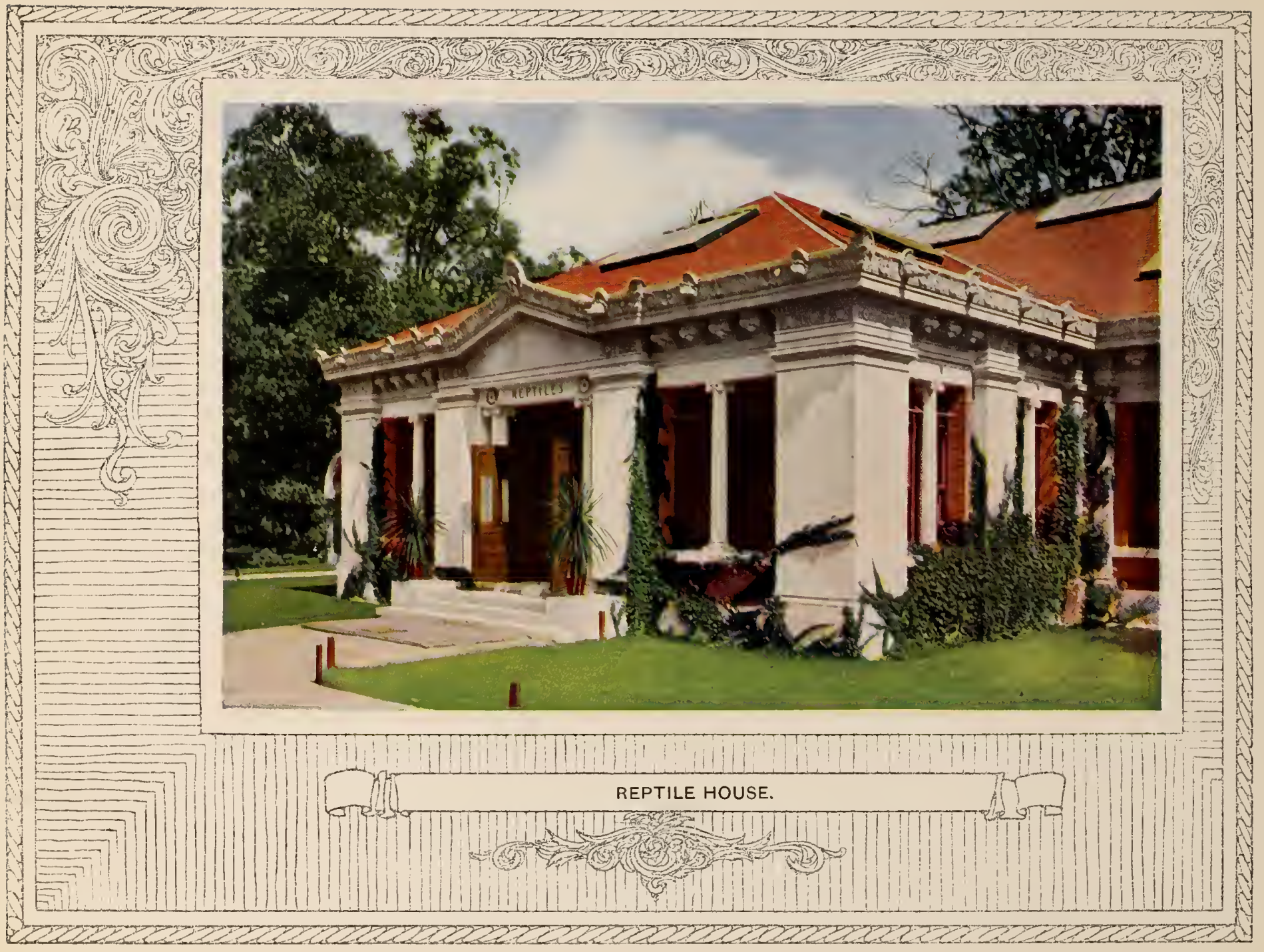




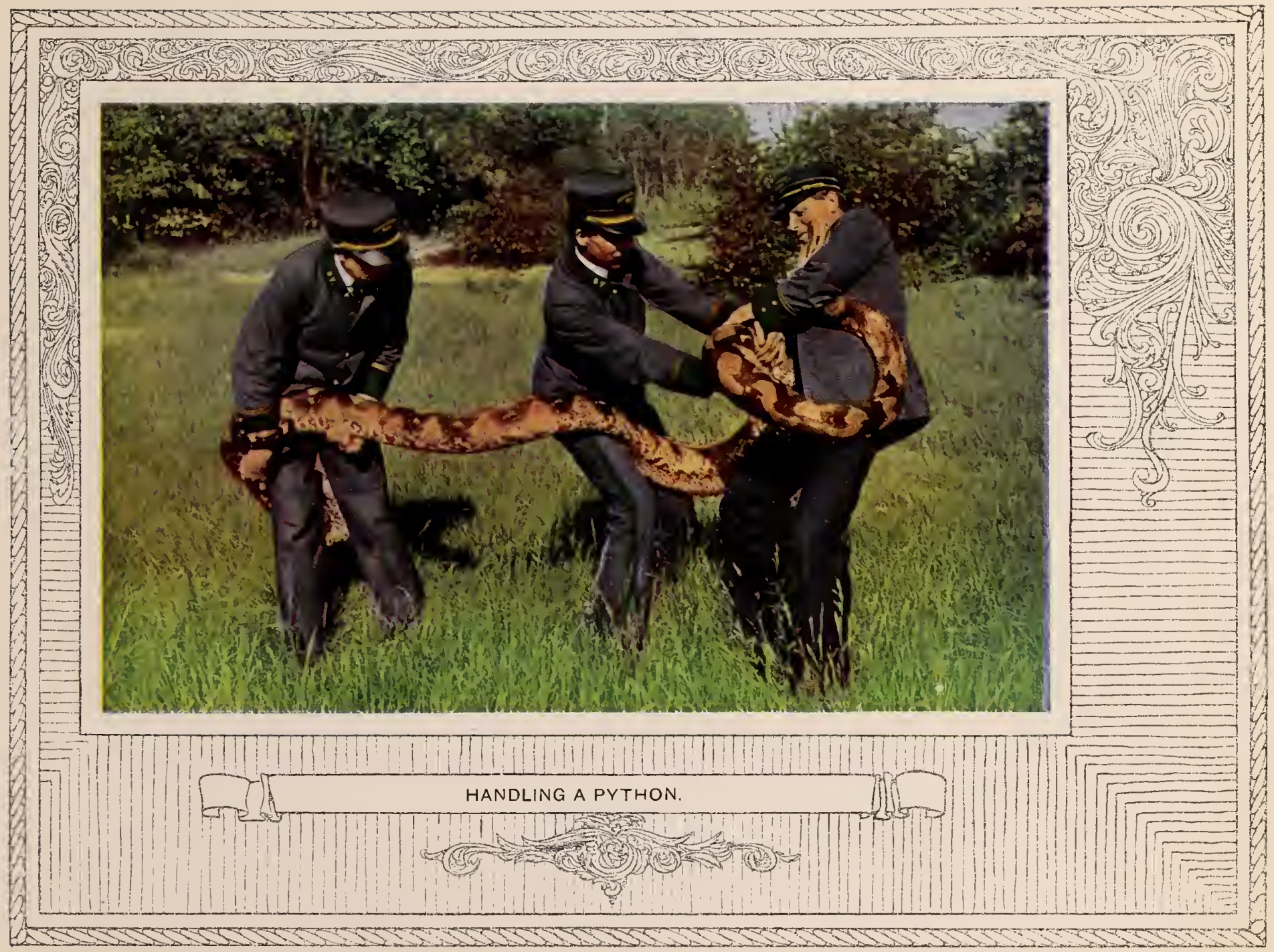




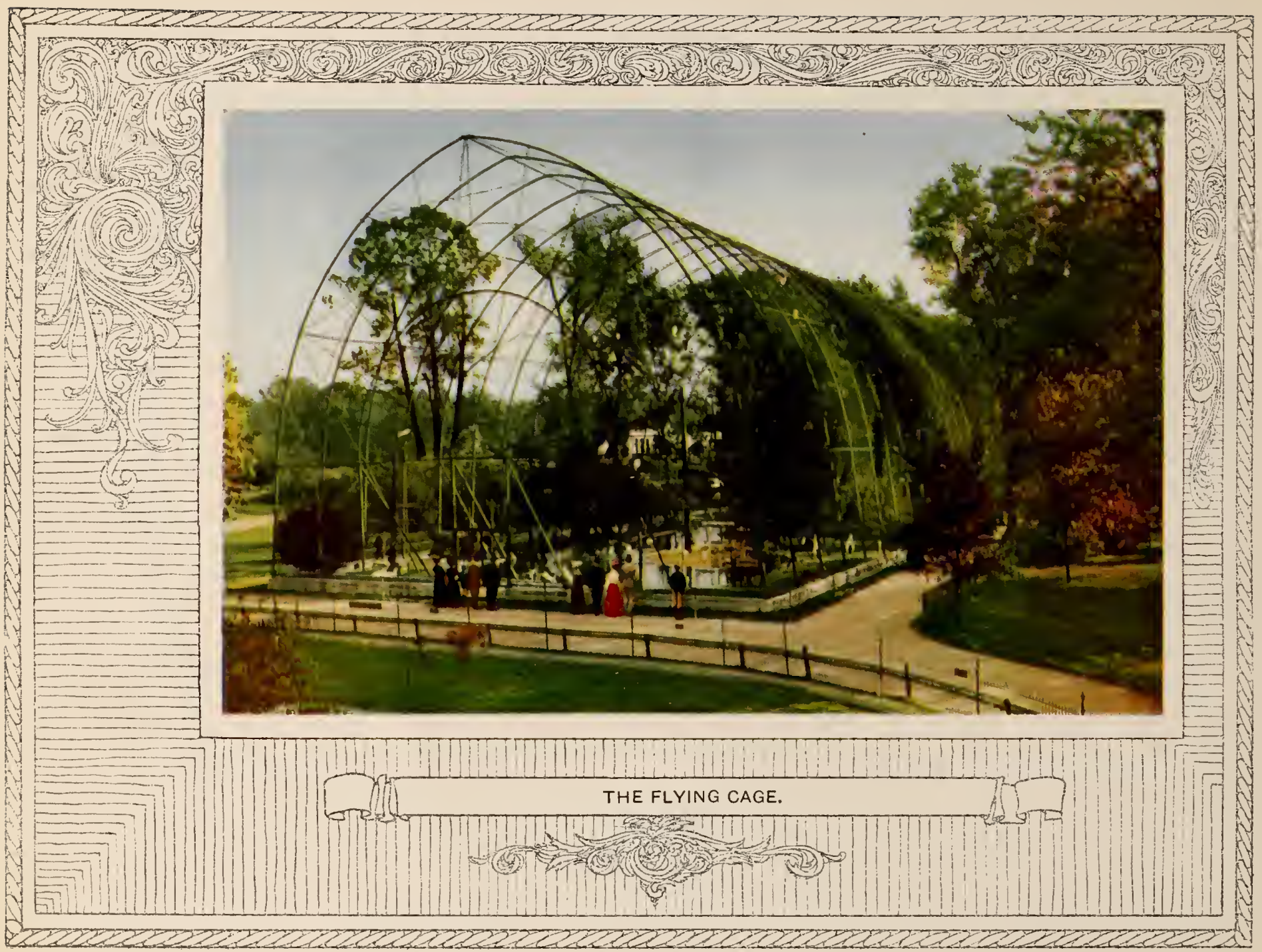




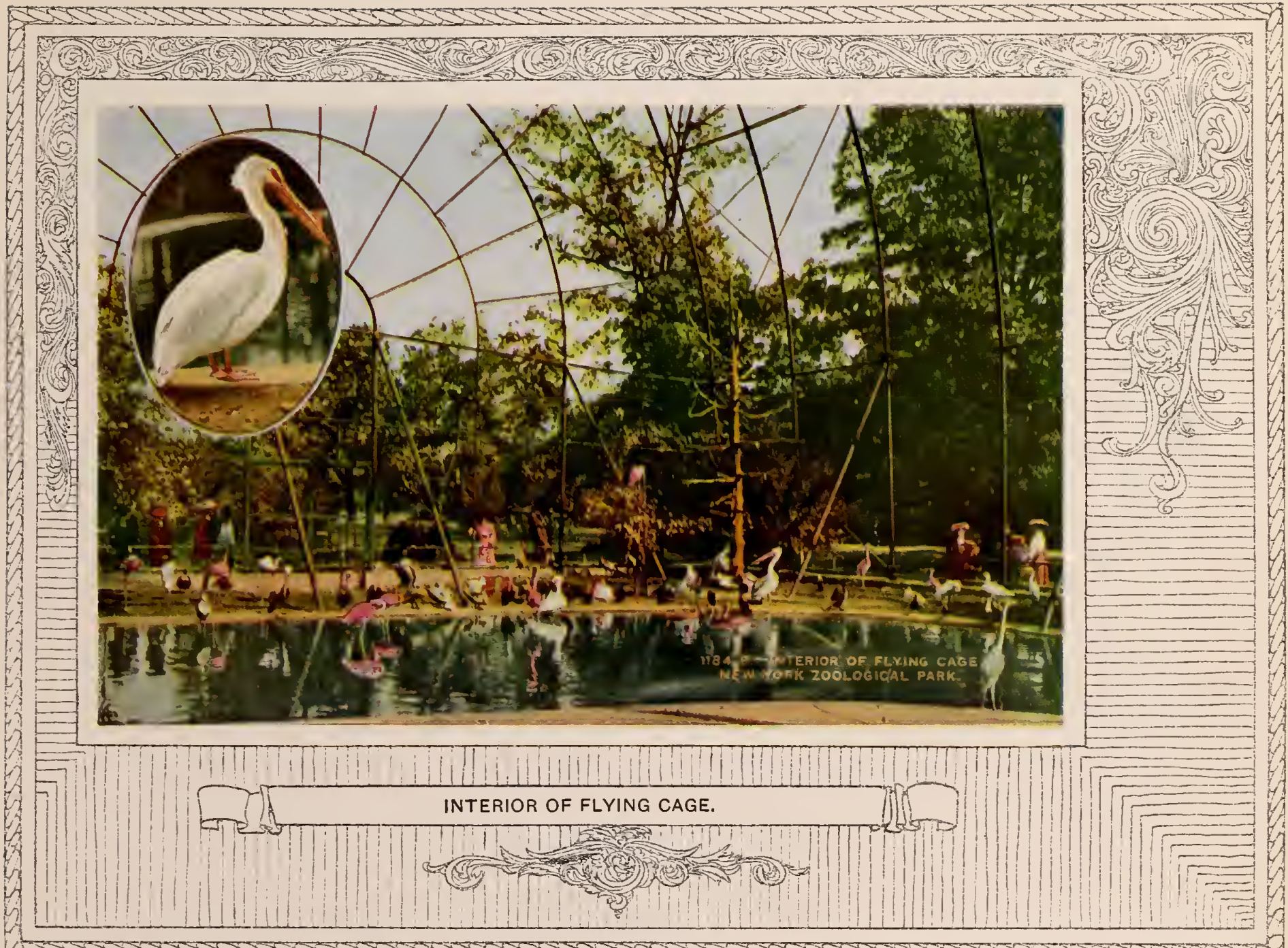

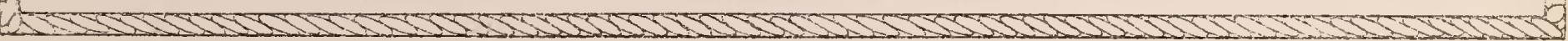




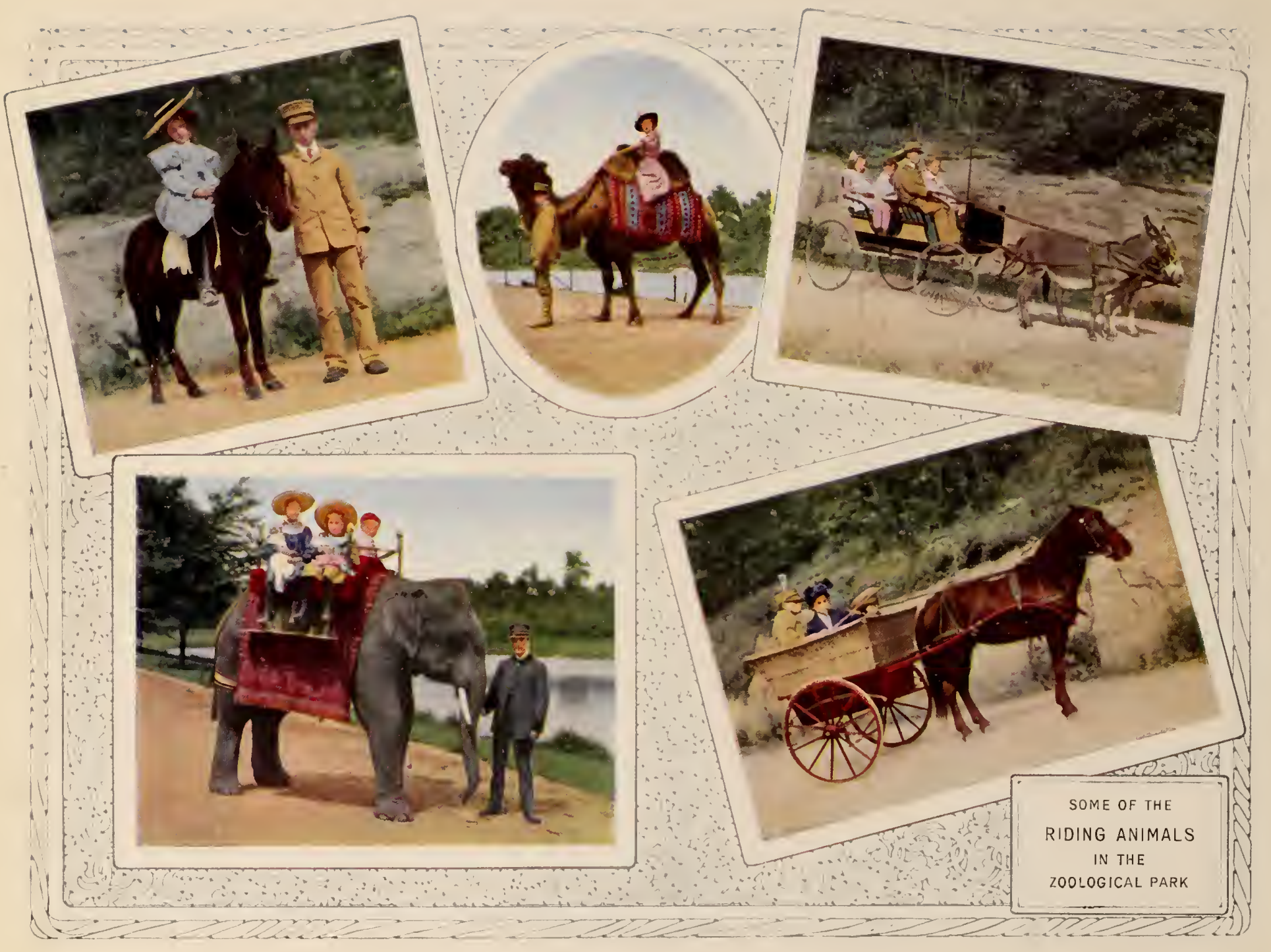



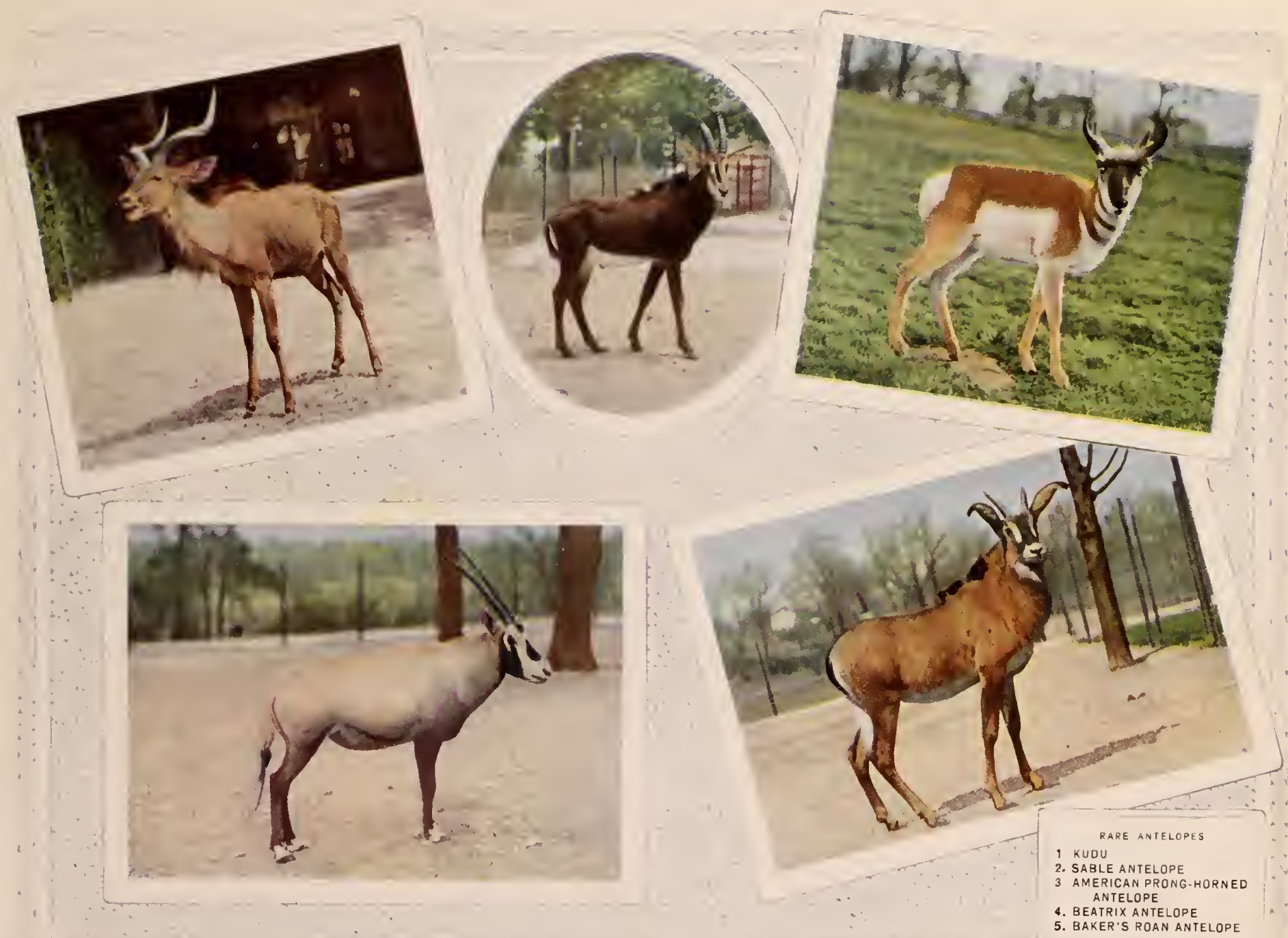

5. BAKER'S ROAN ANTELOPE

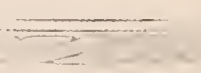




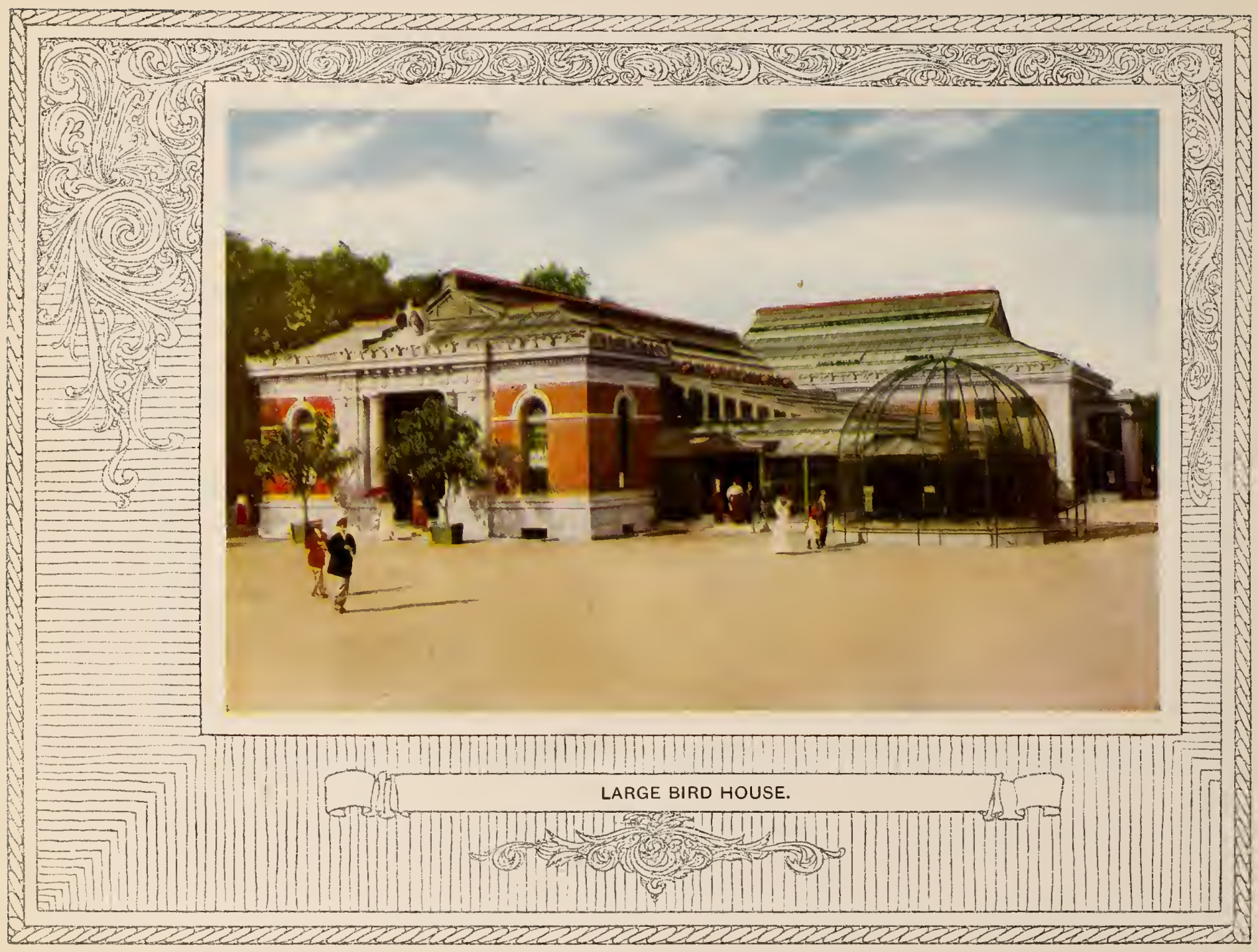




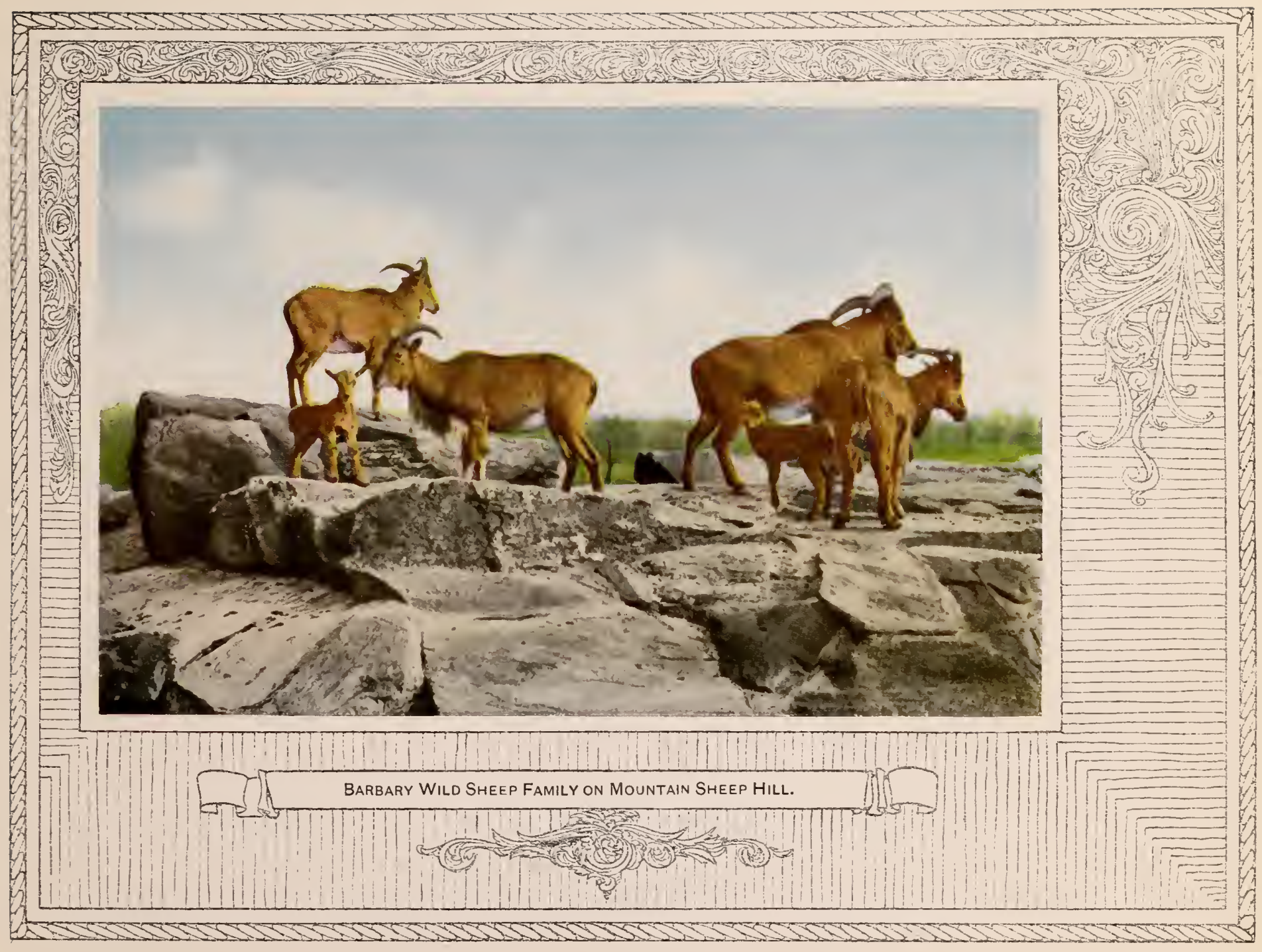




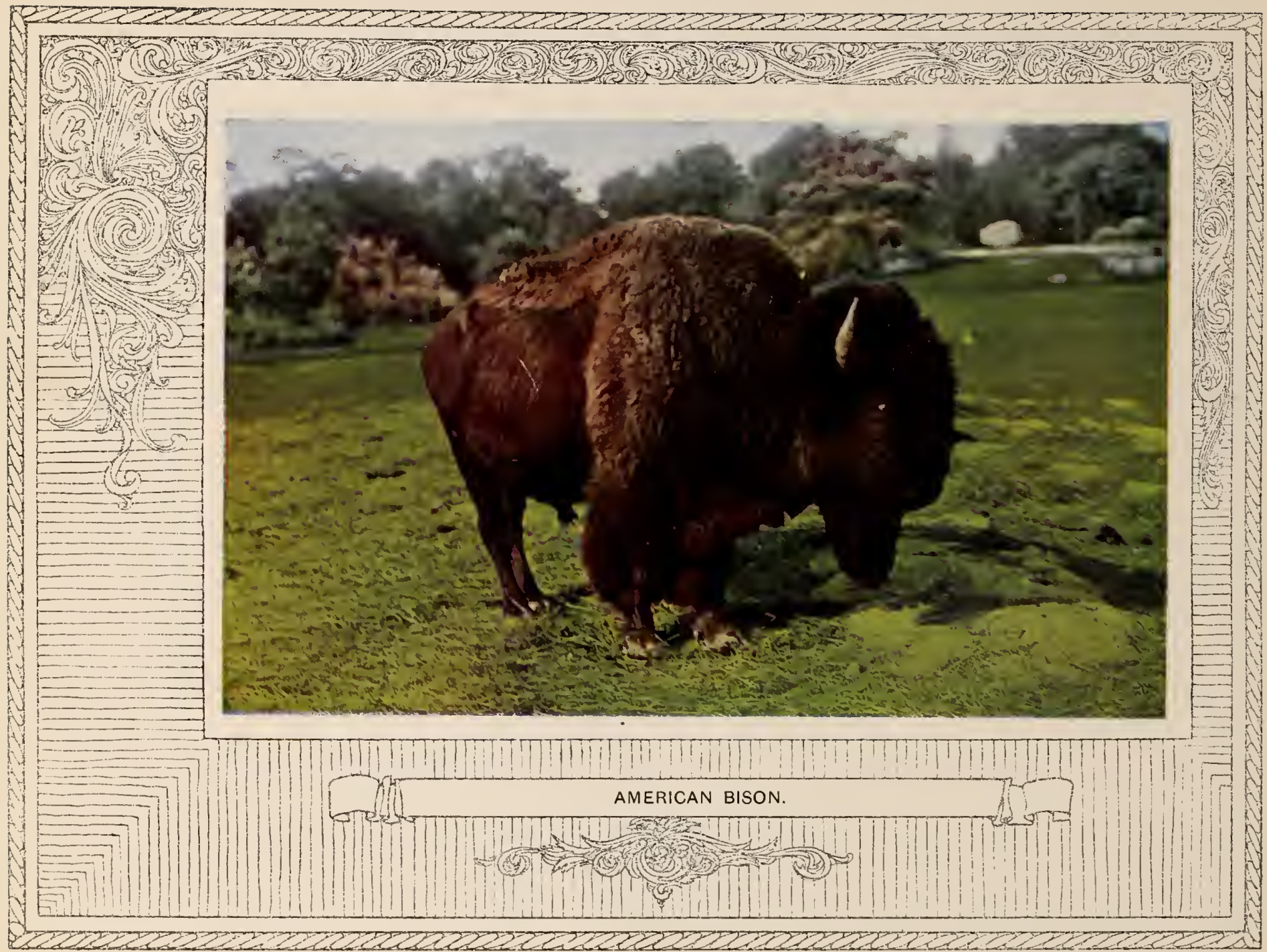




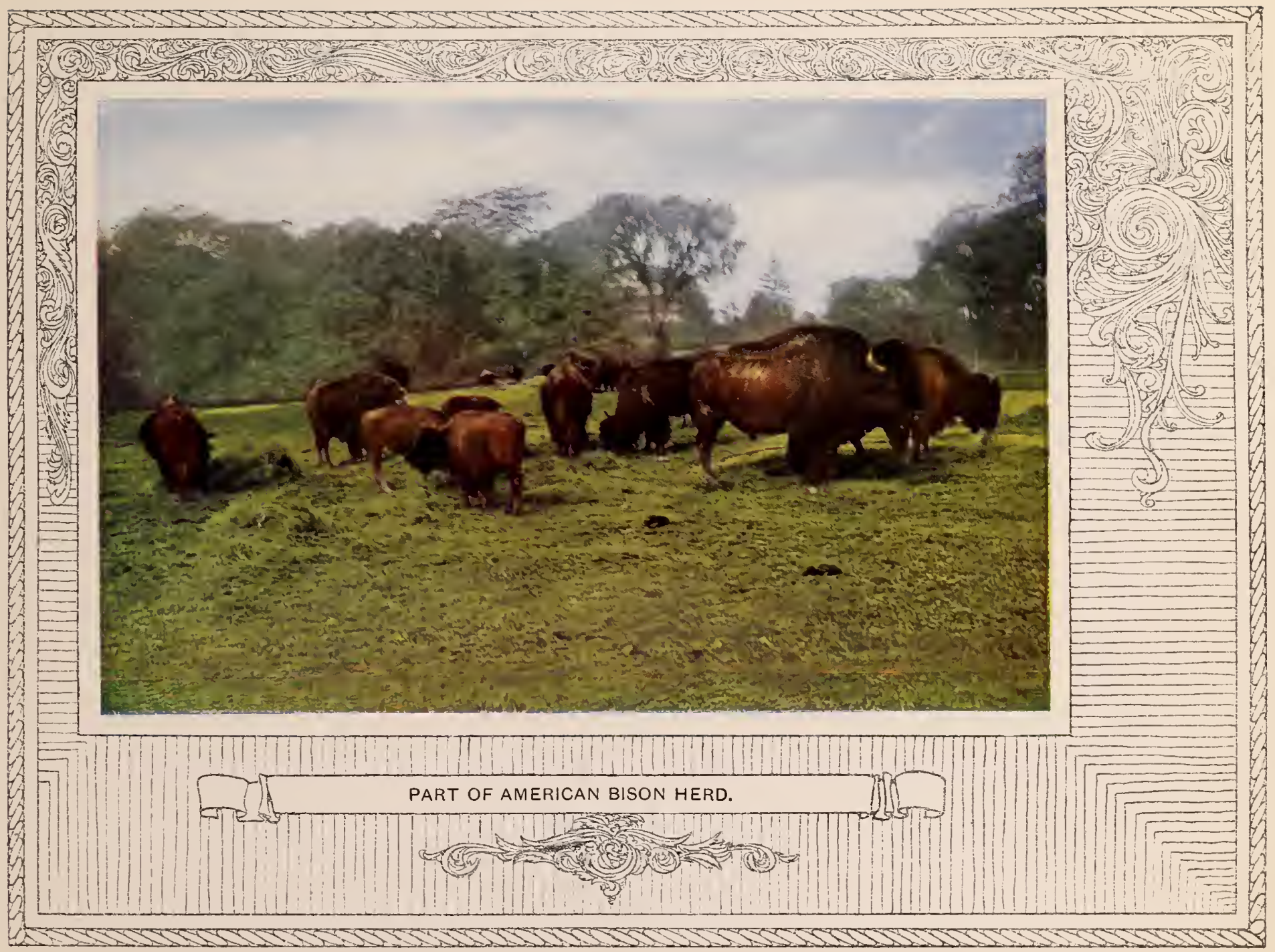




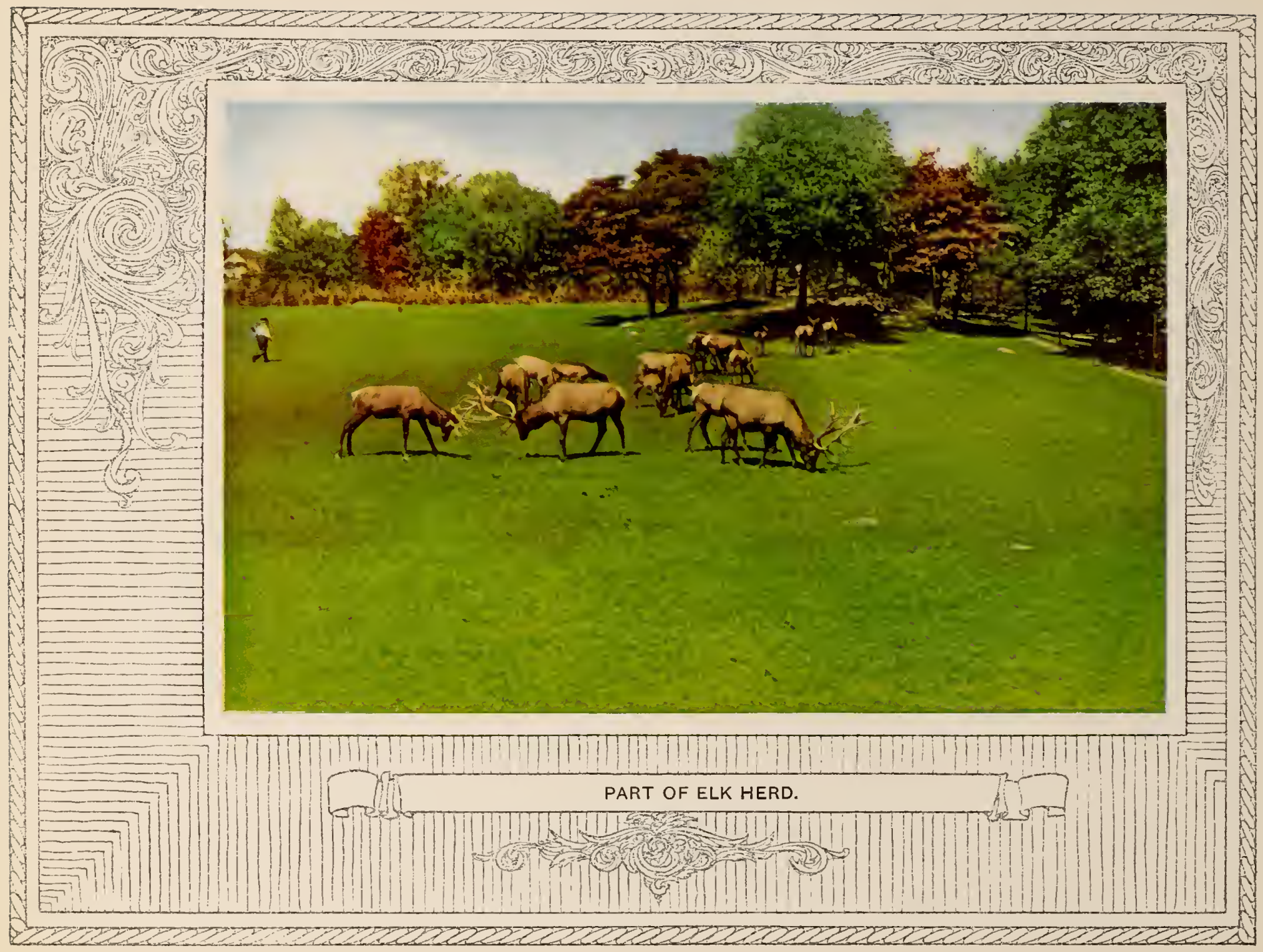




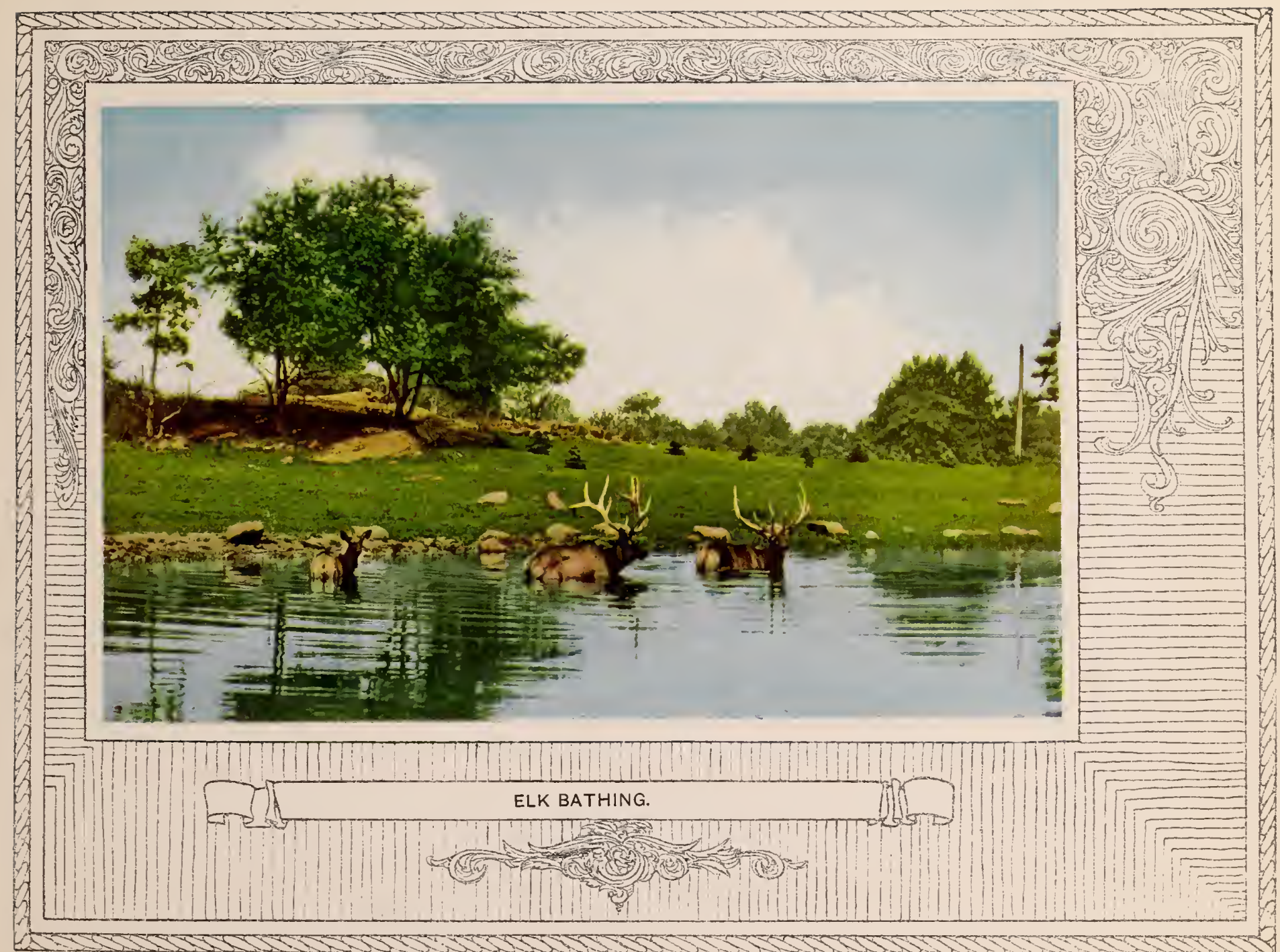




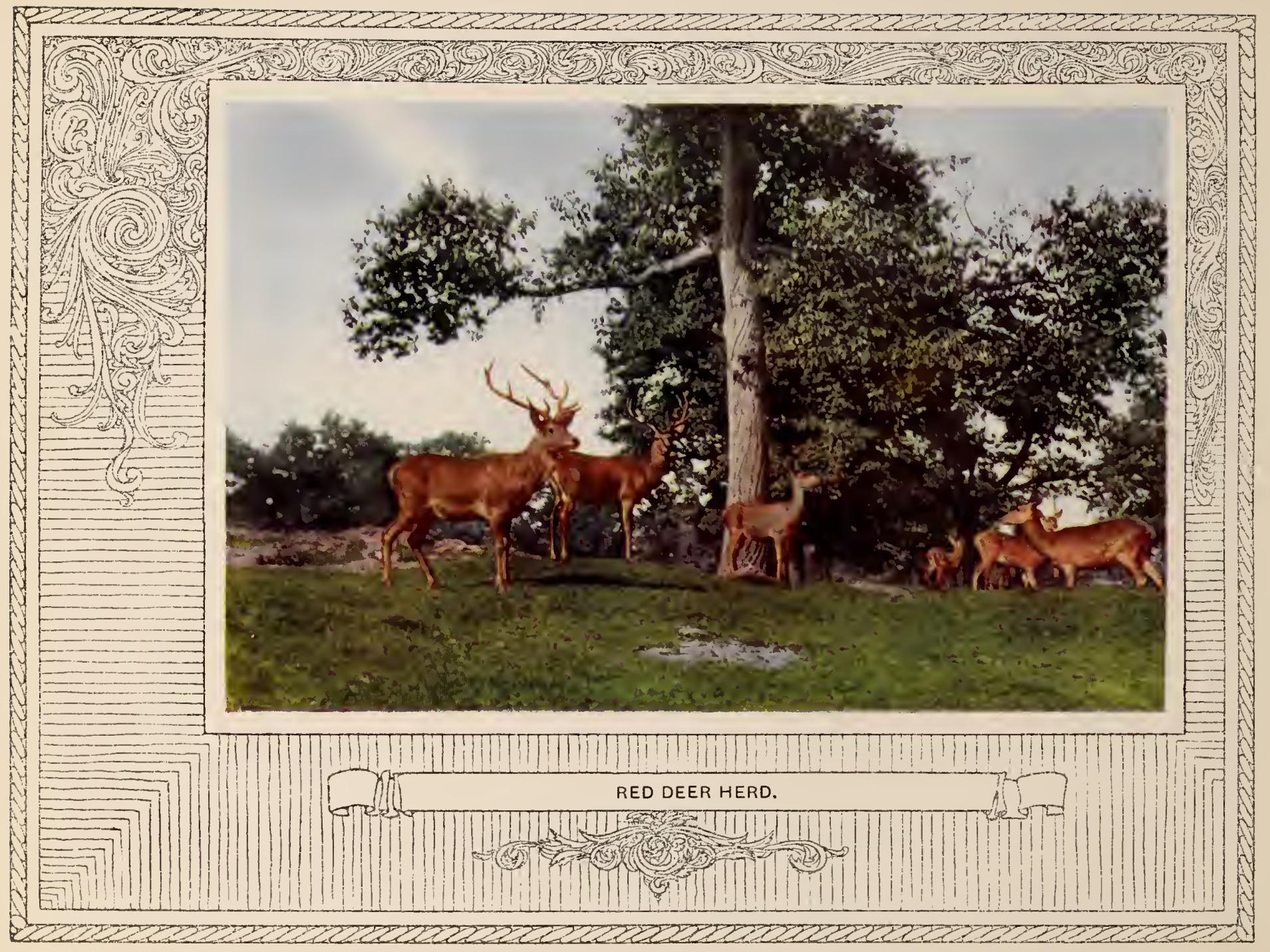




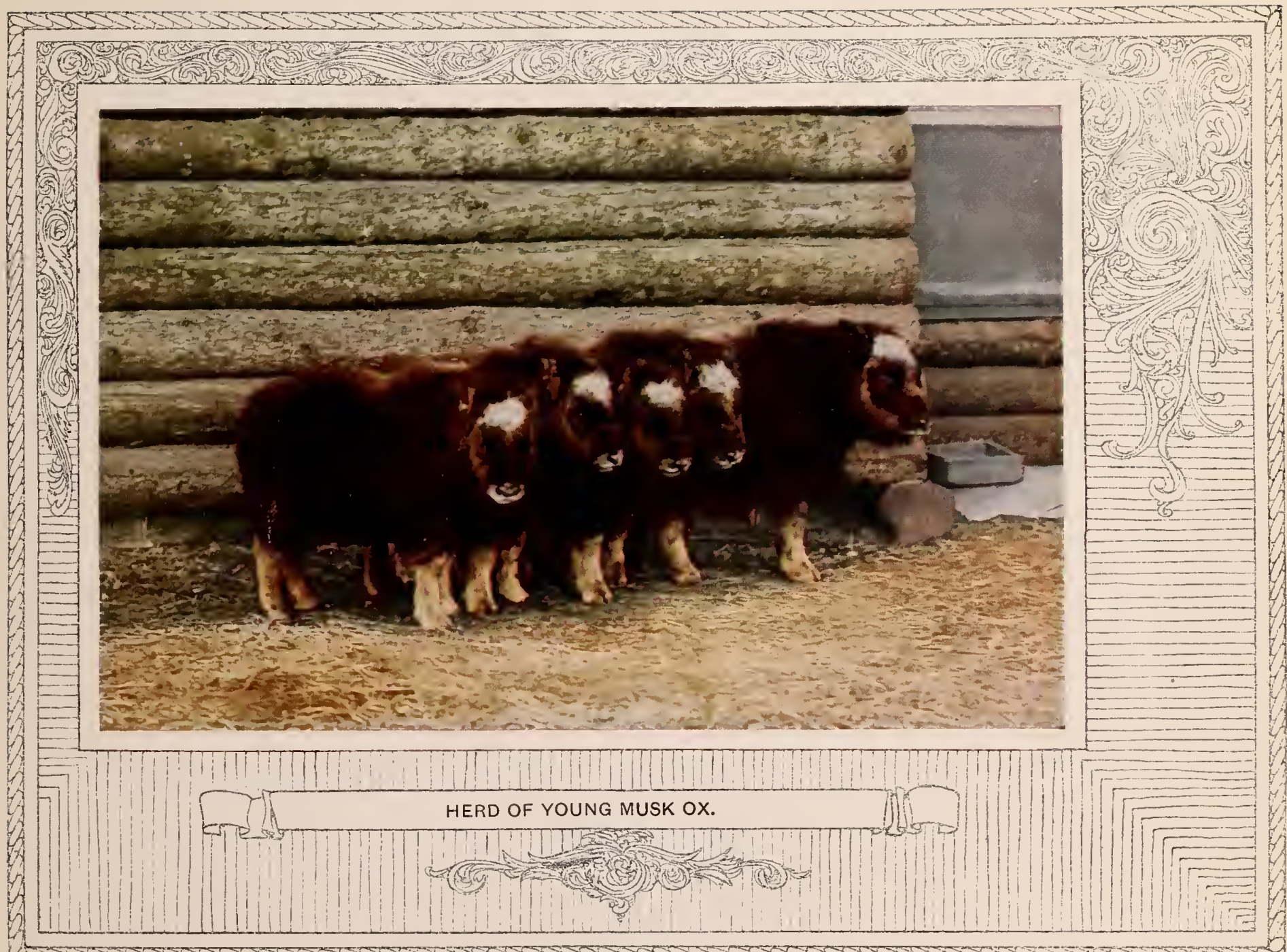

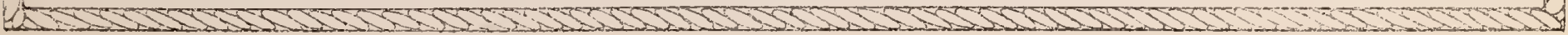




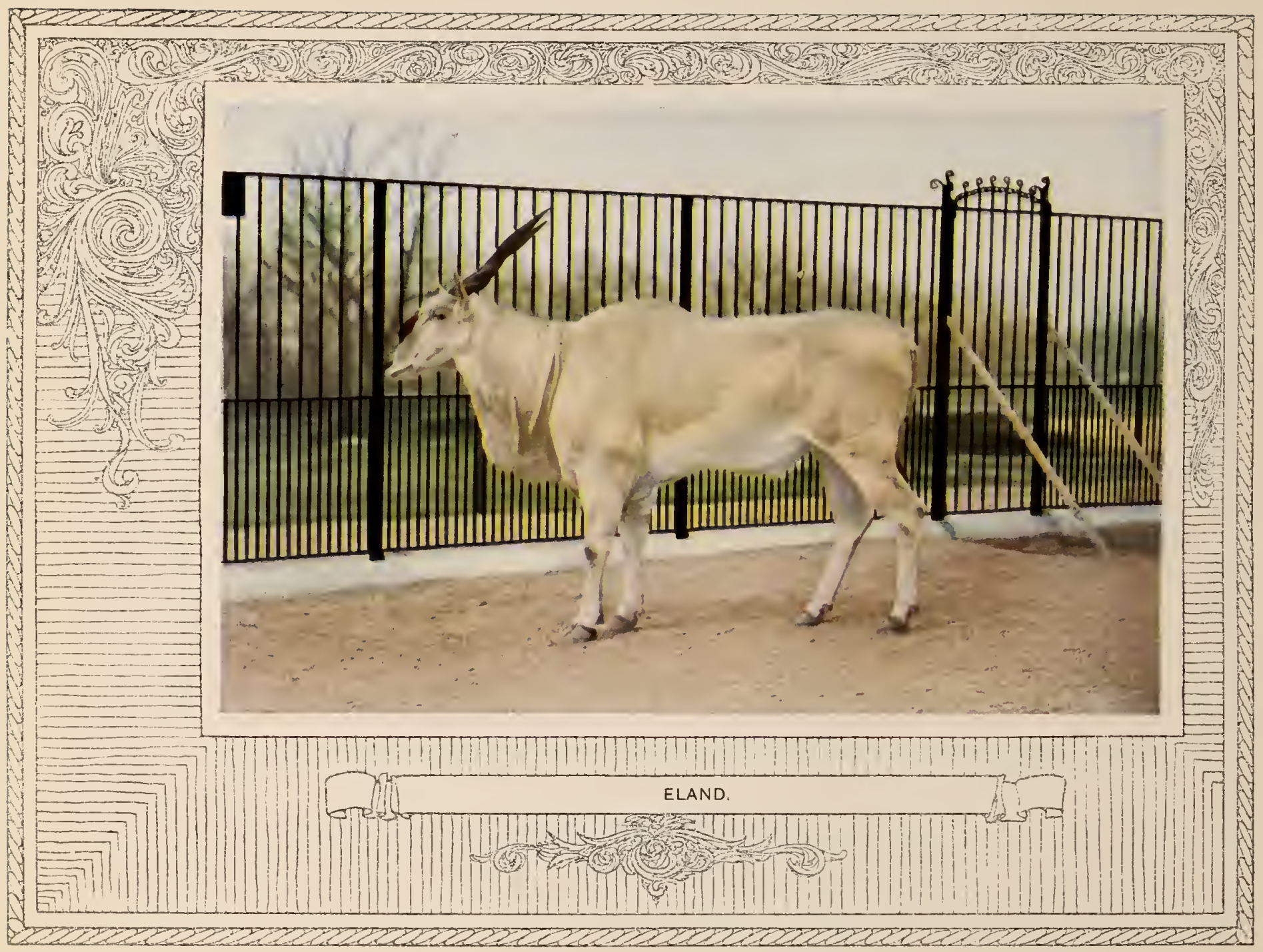




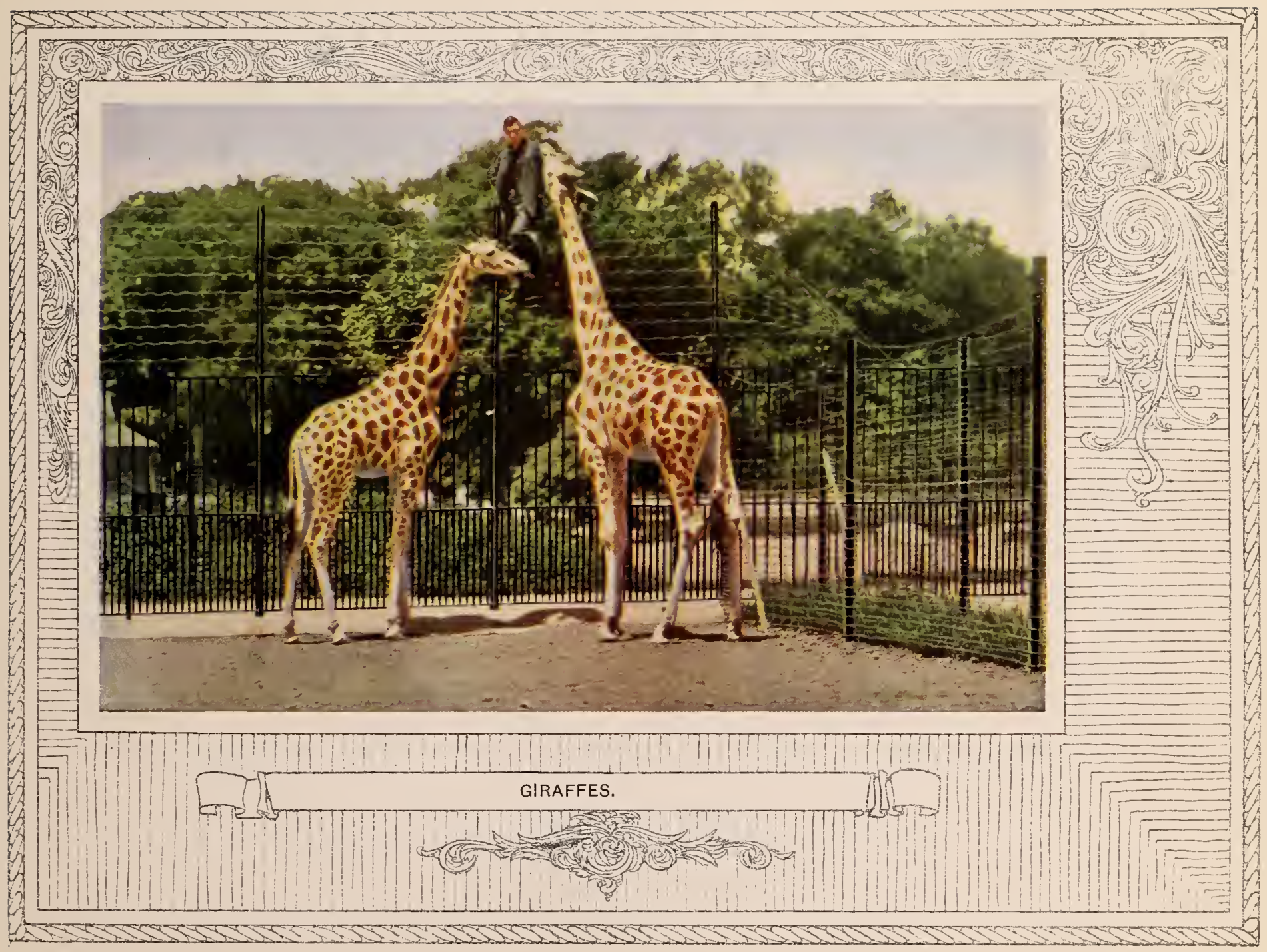




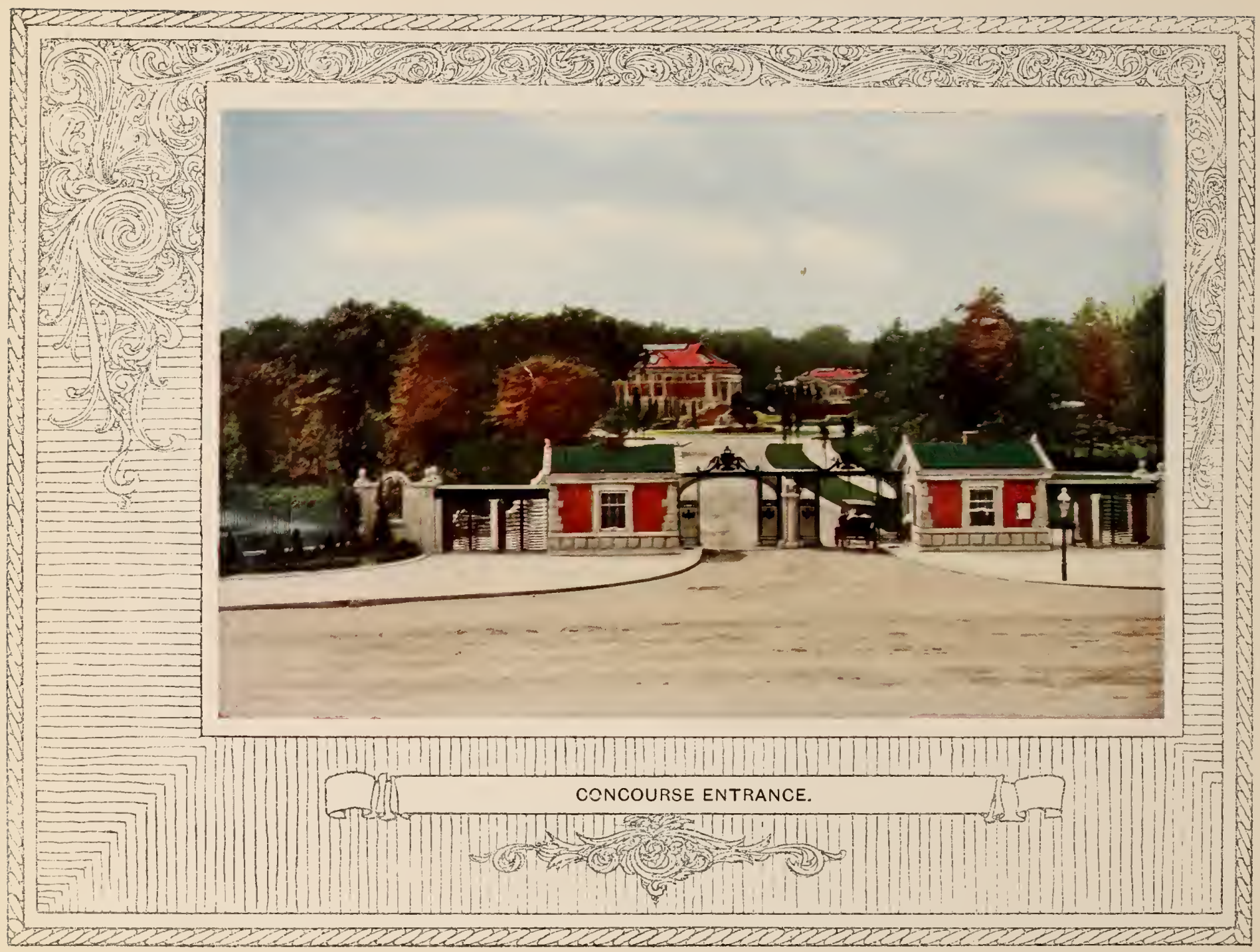




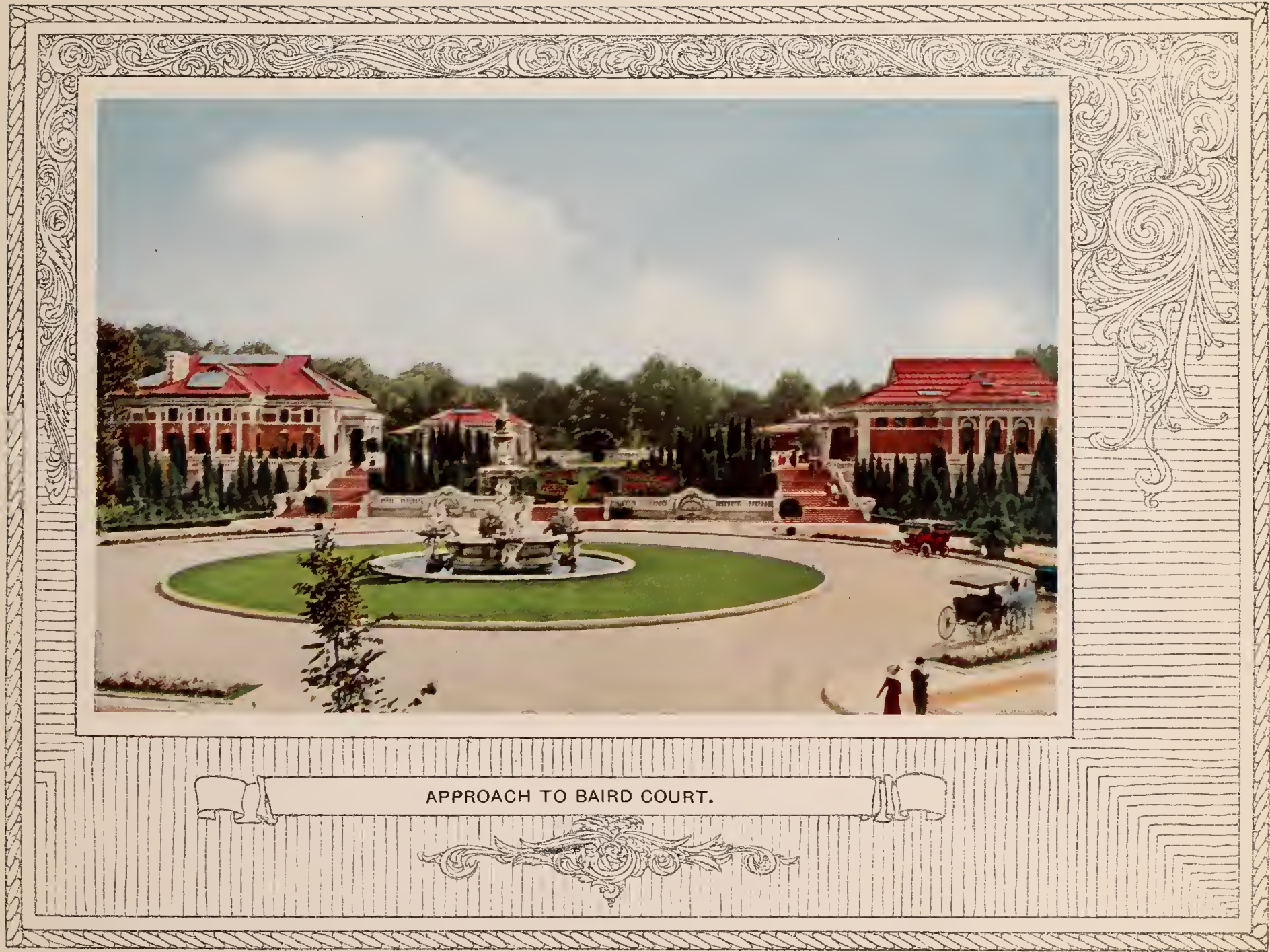




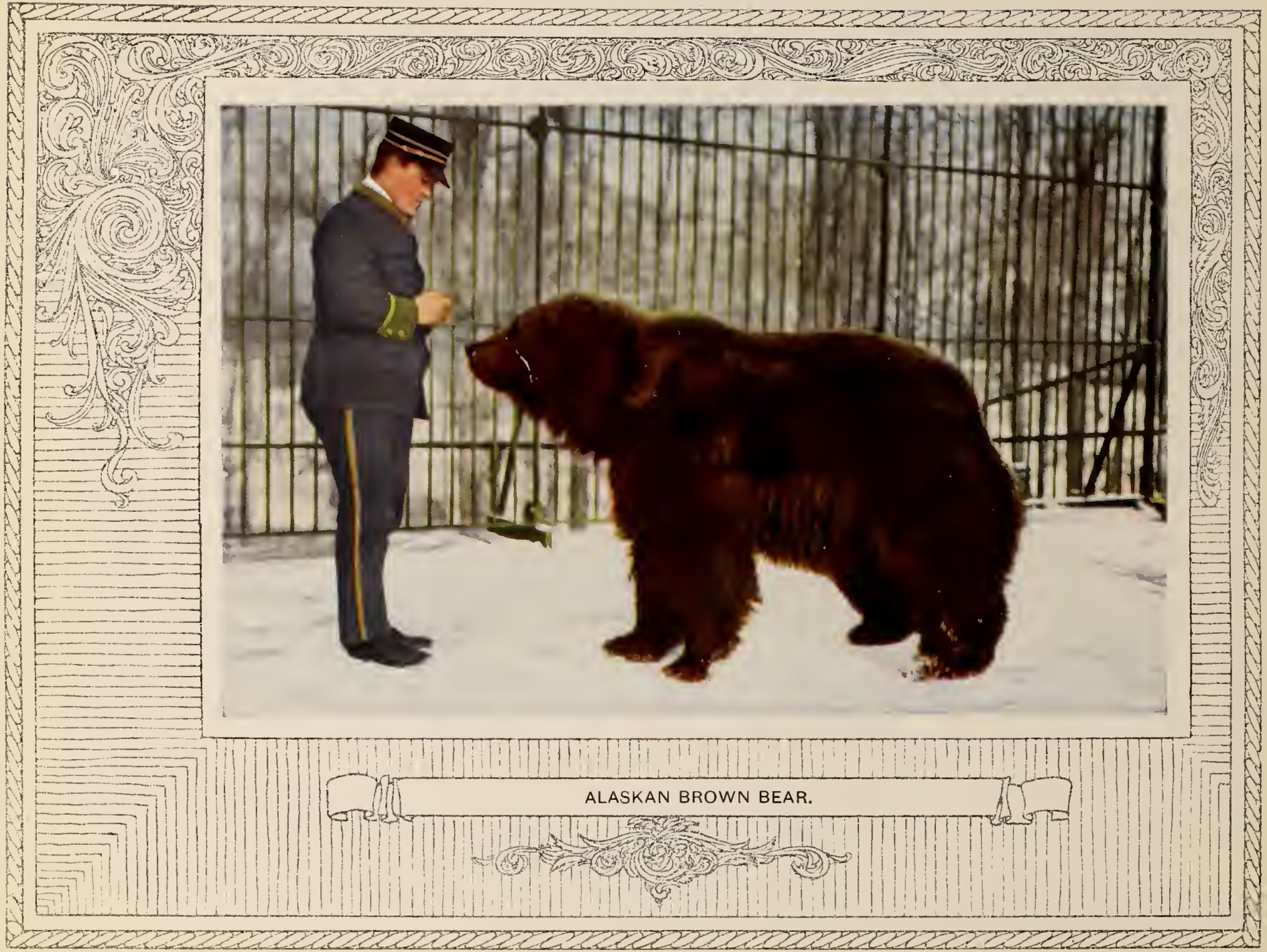




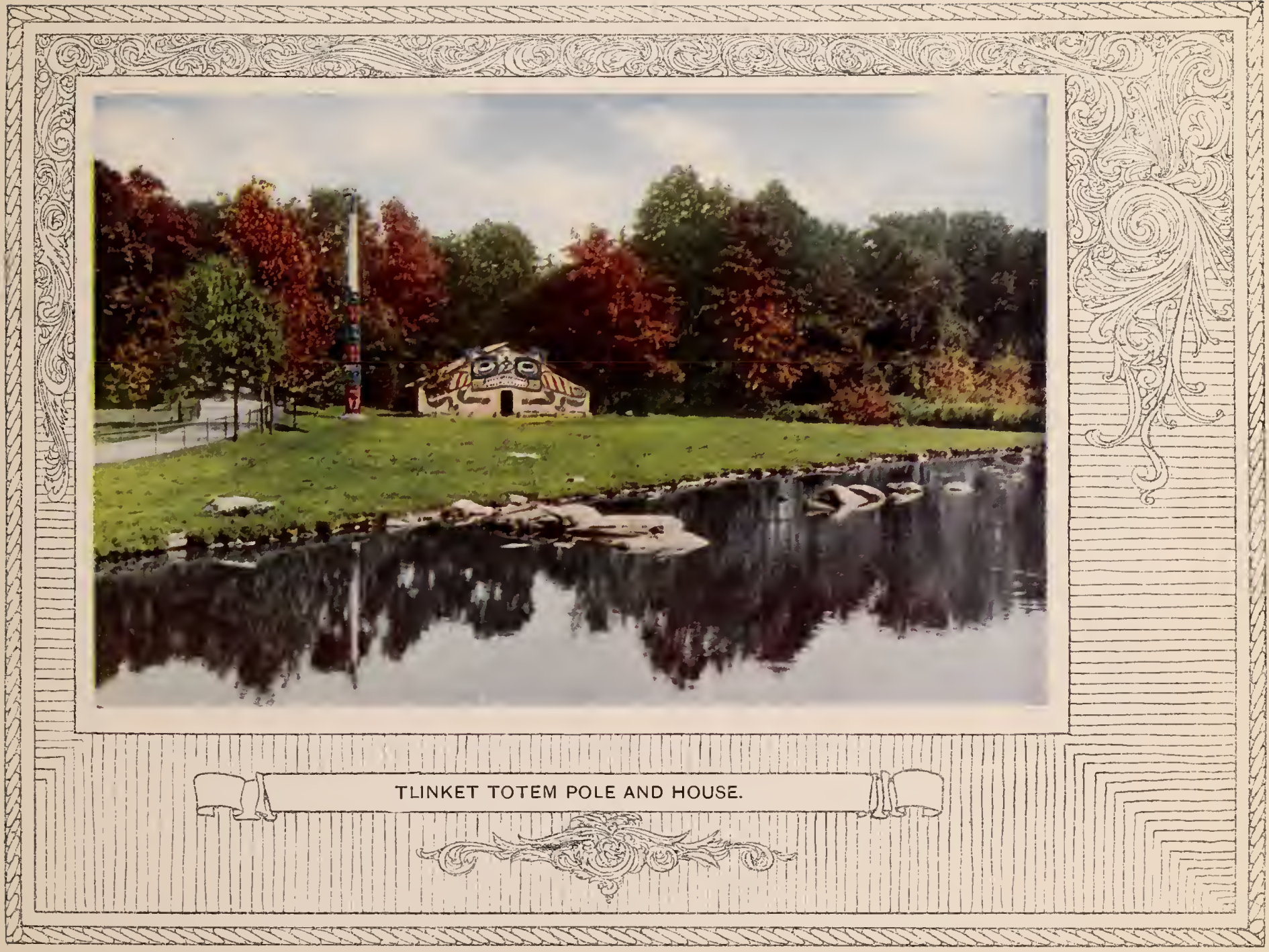




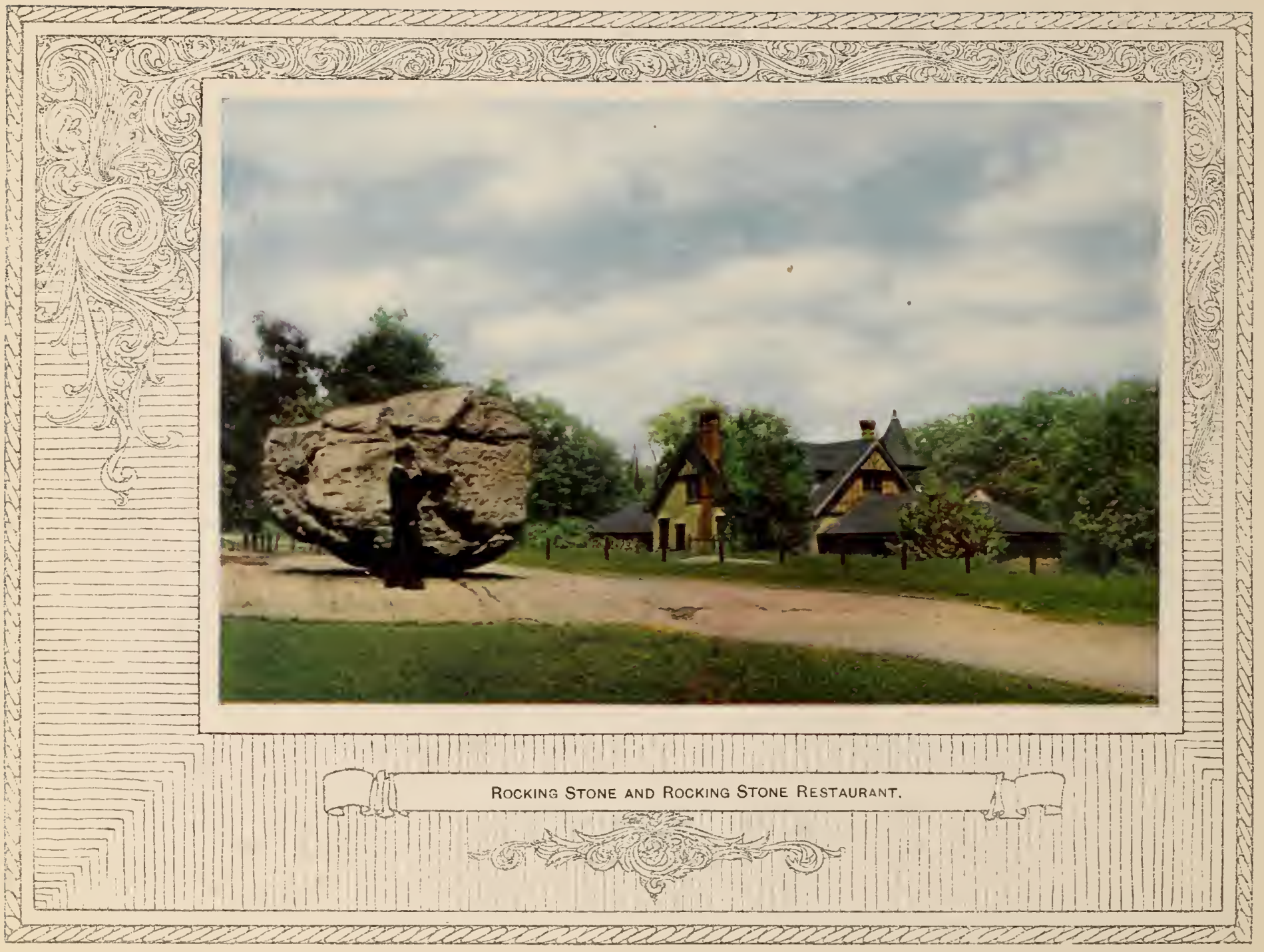




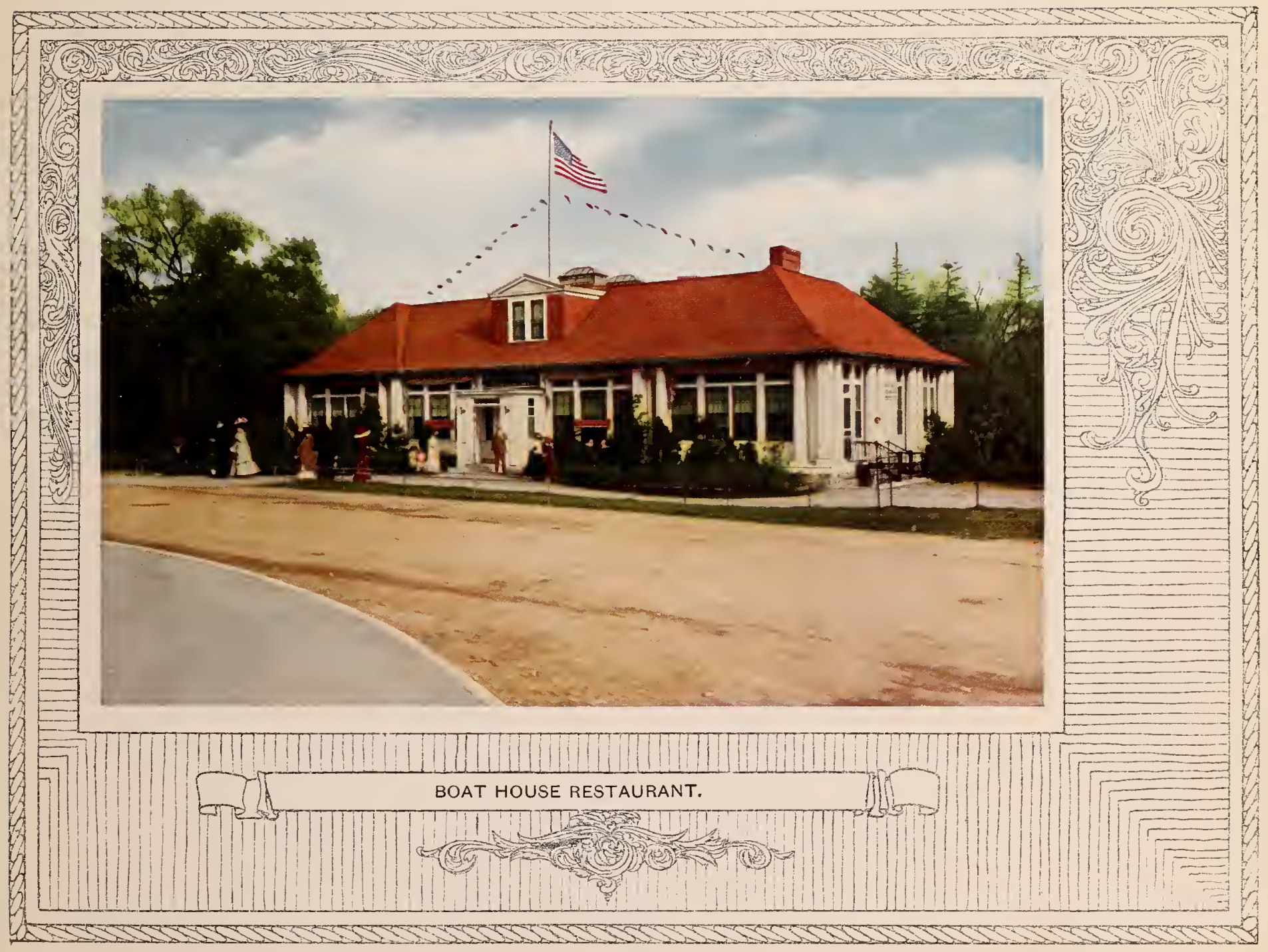




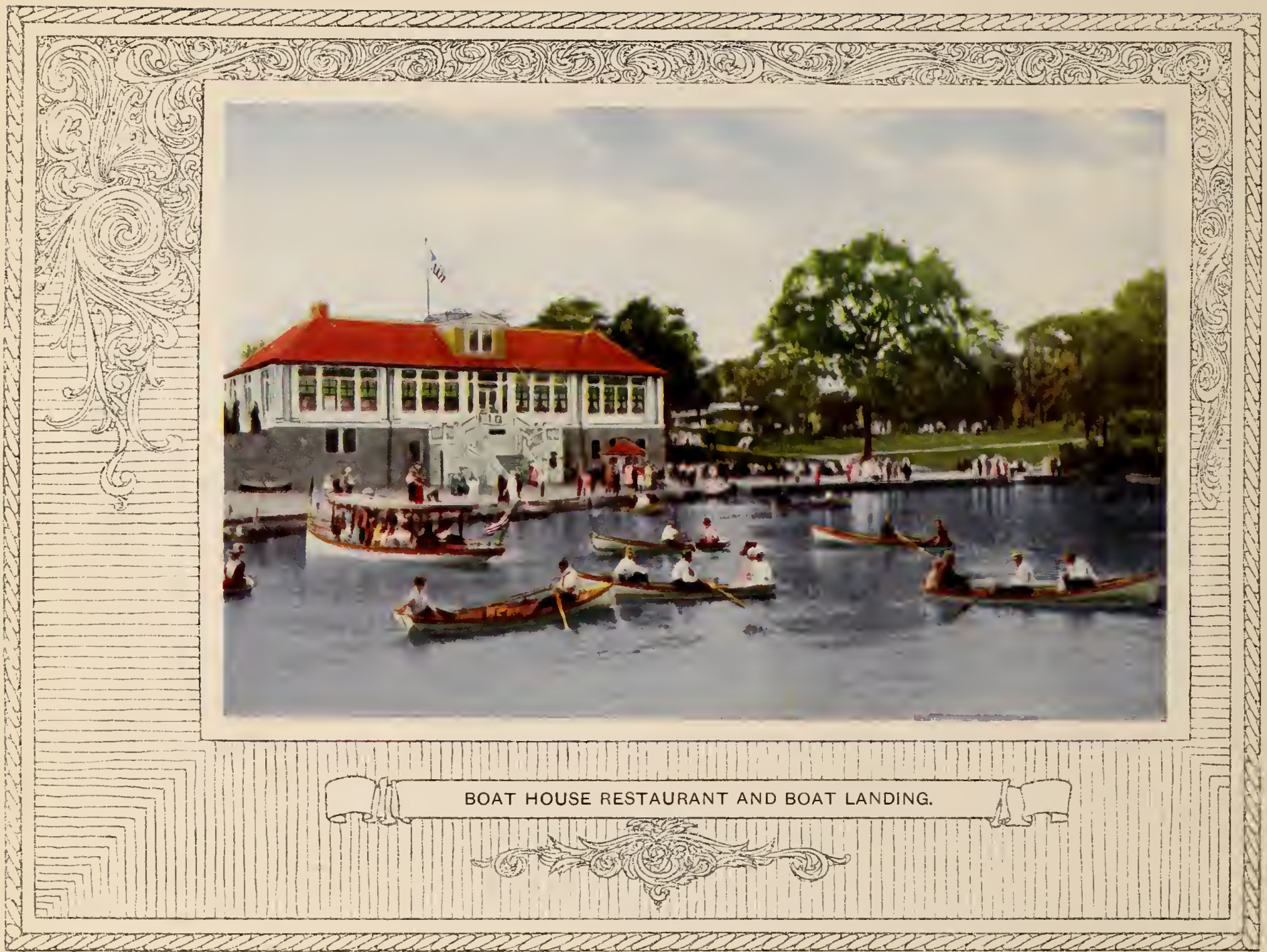




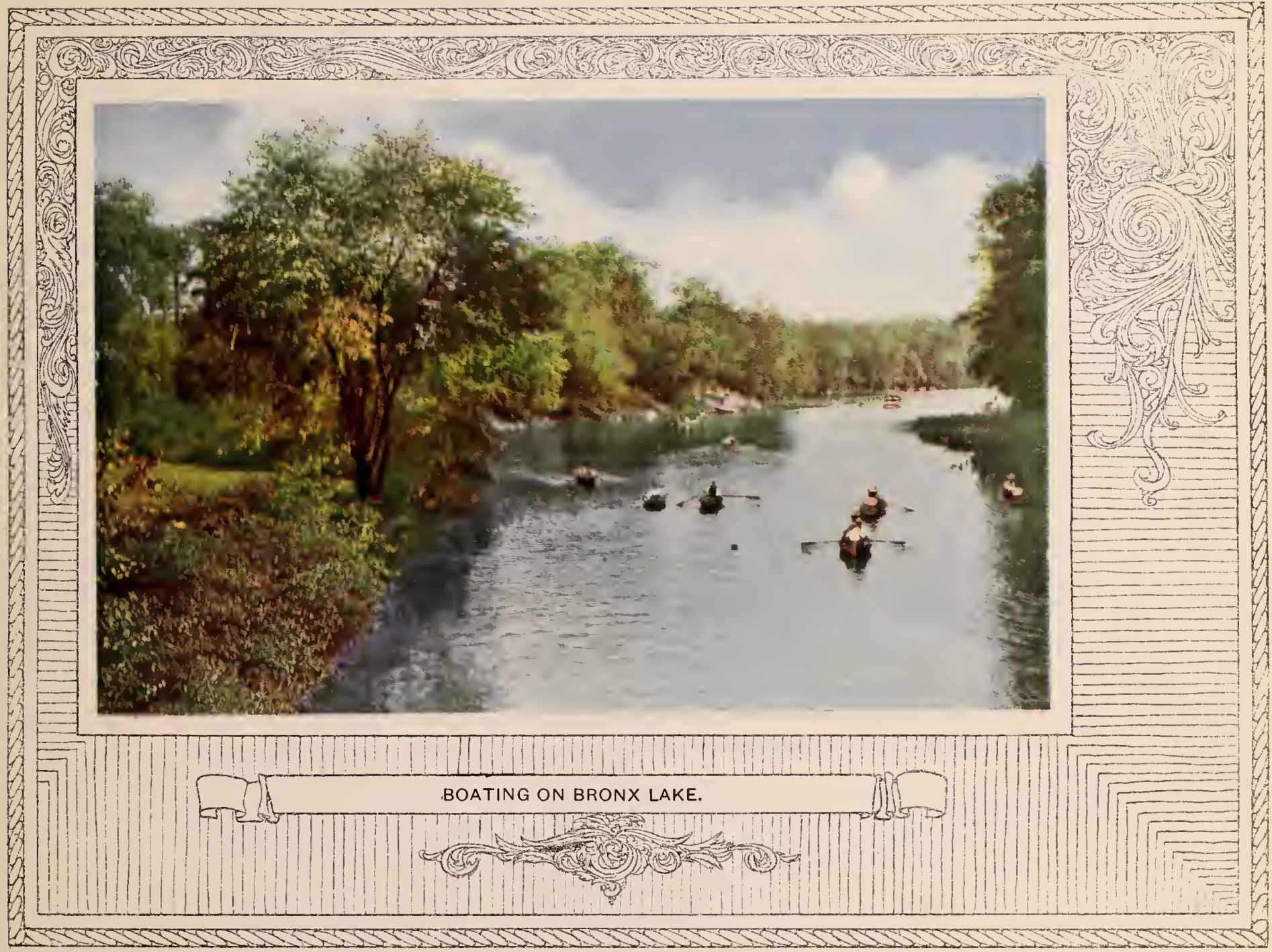




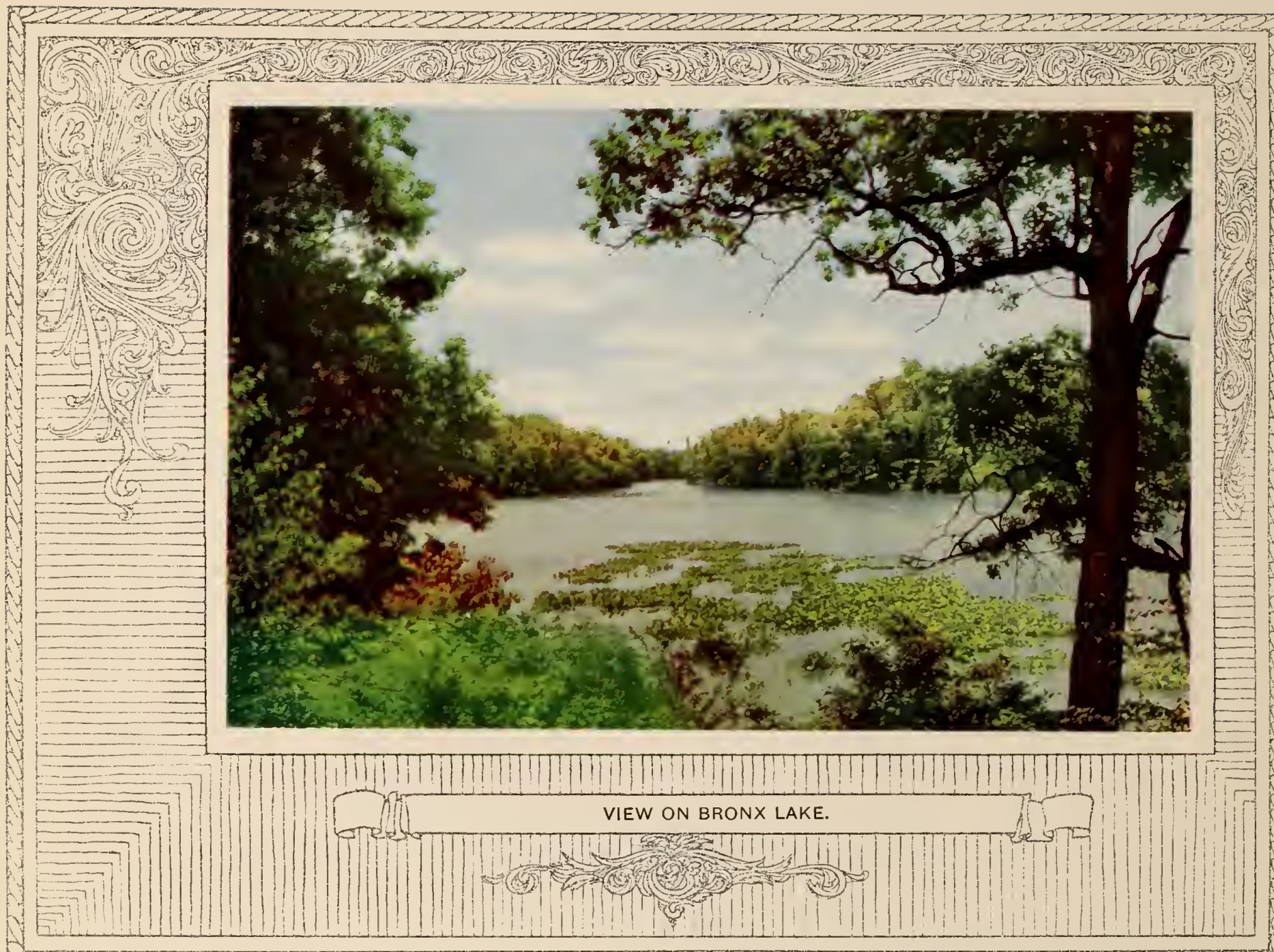

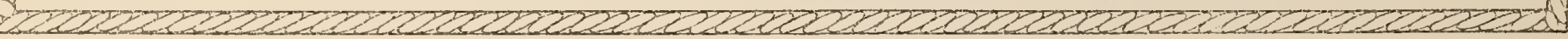




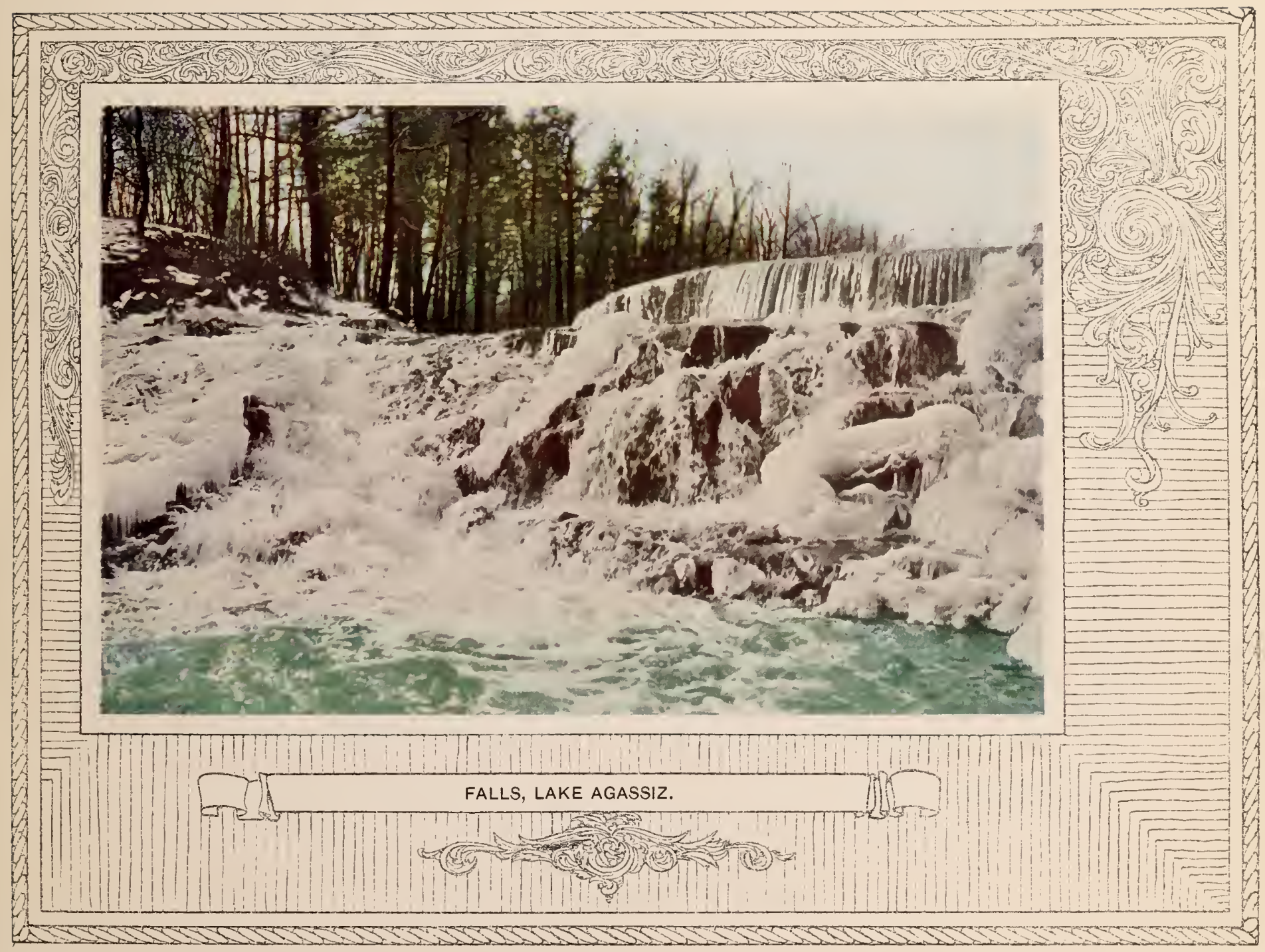




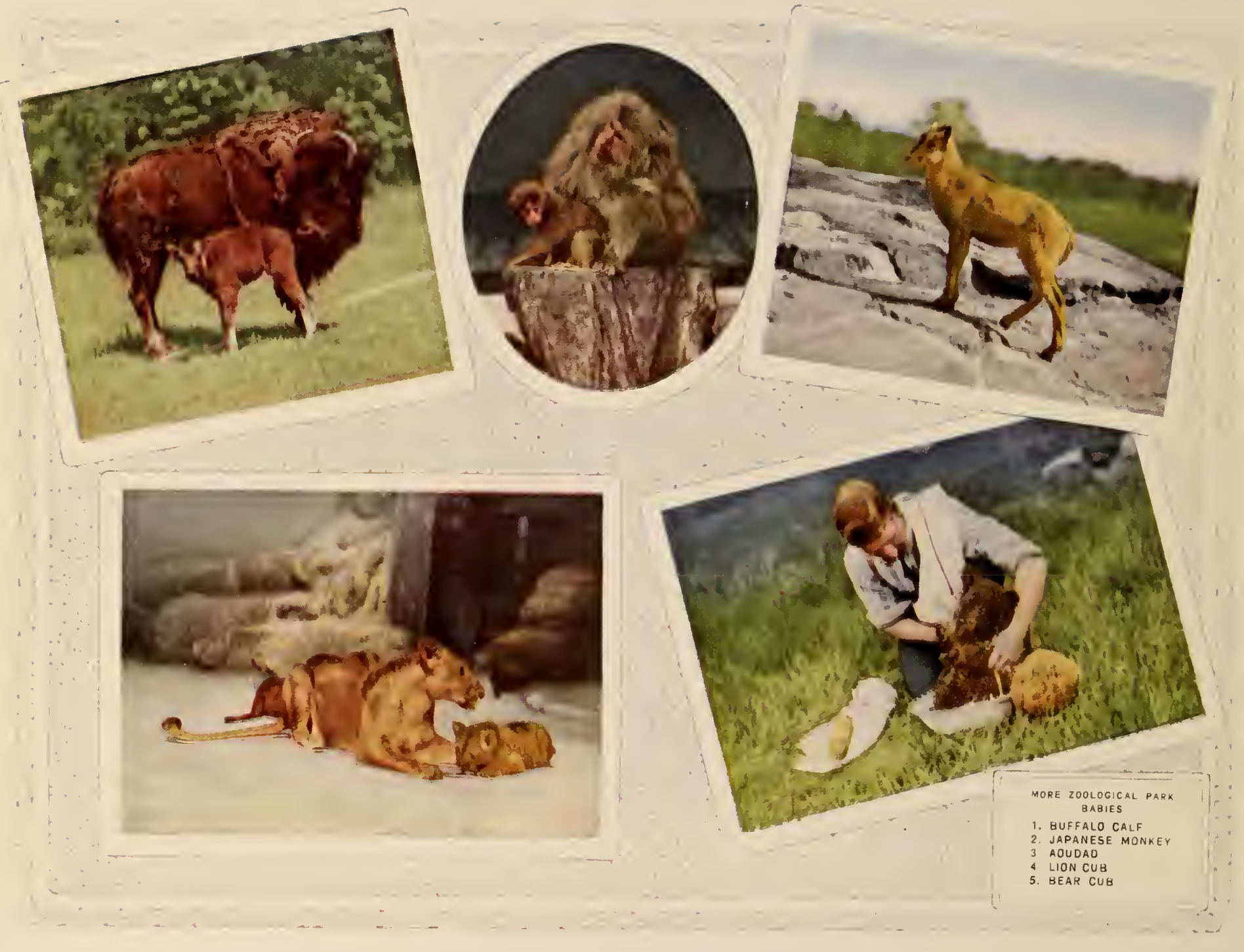




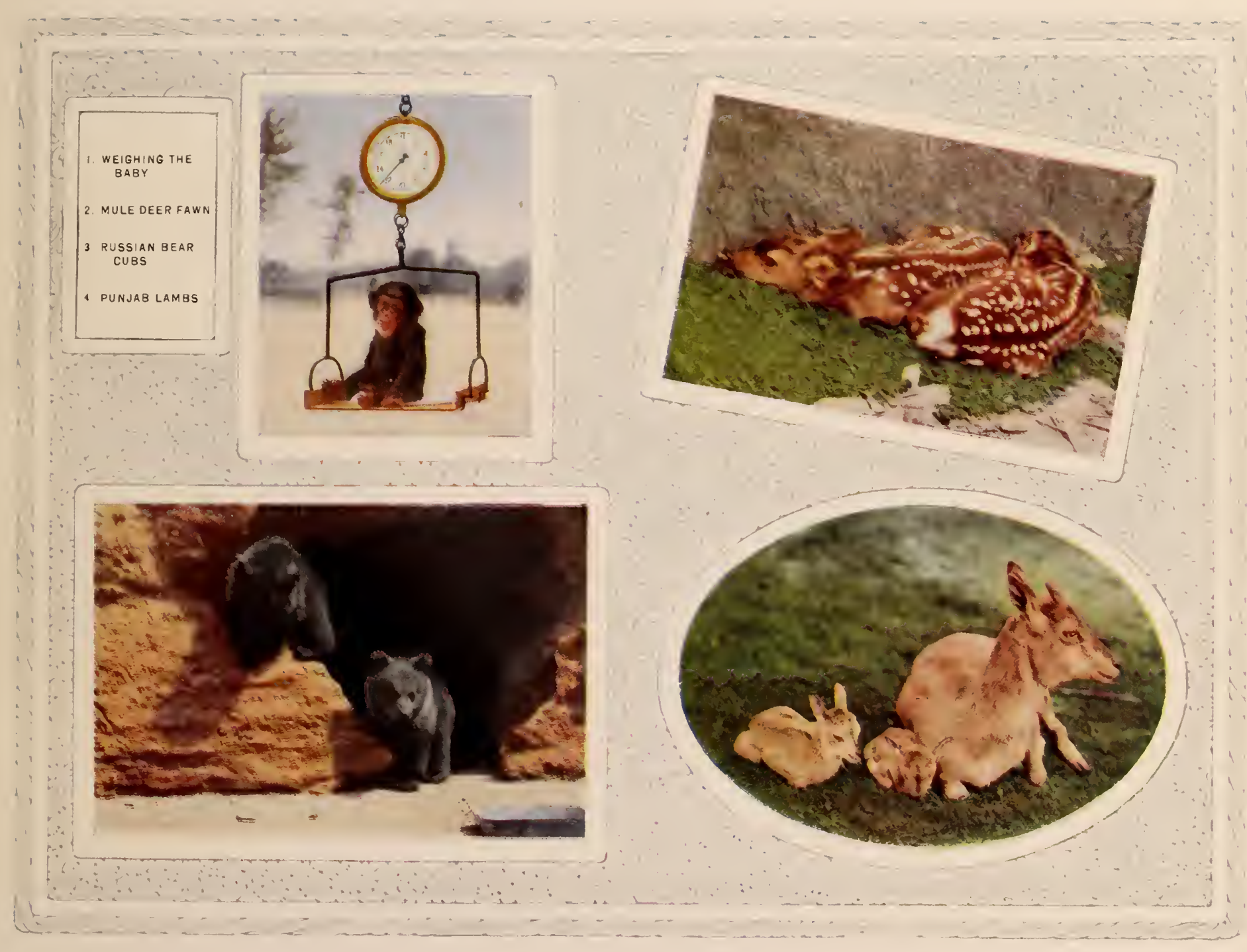




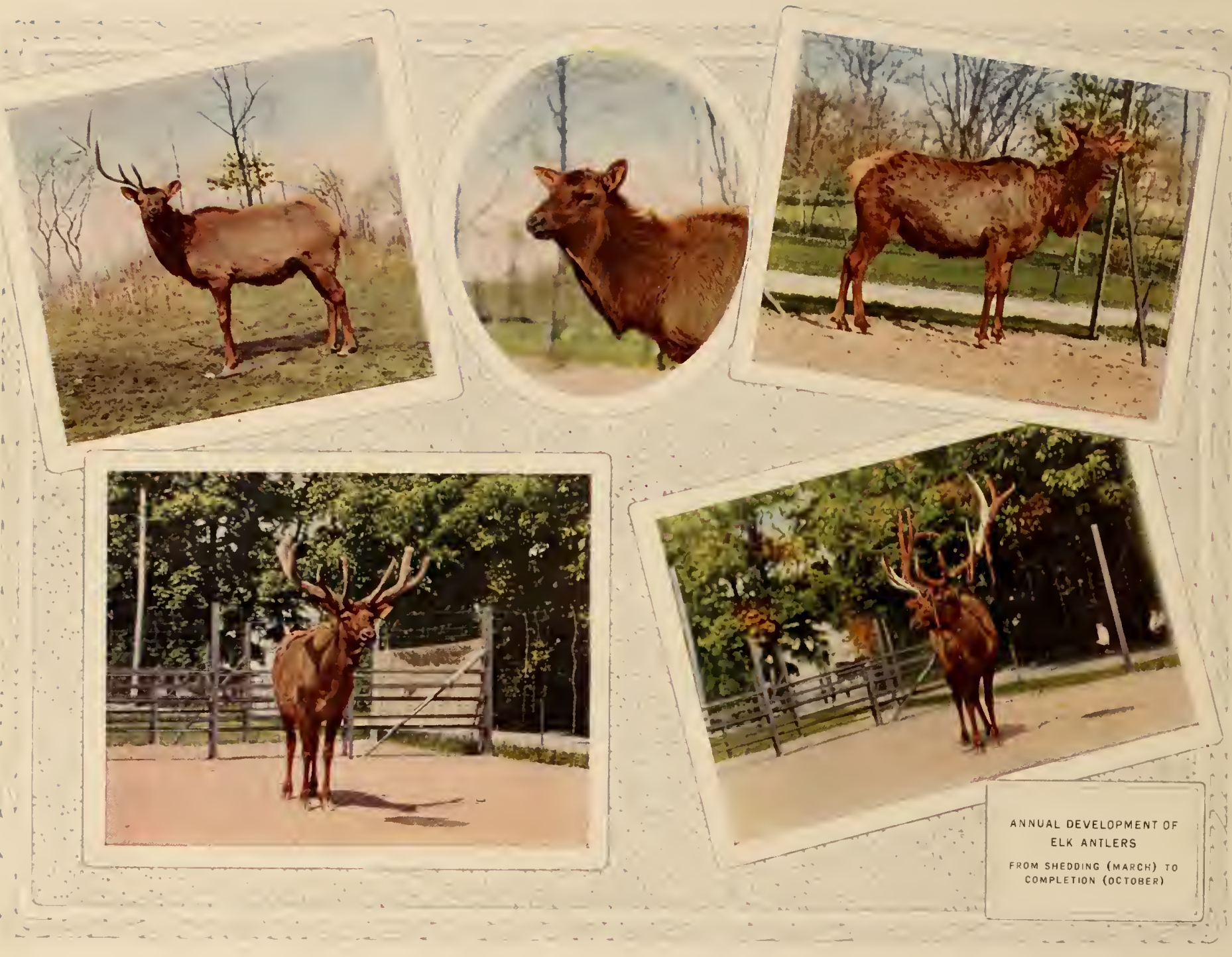


AVERY

cussios 


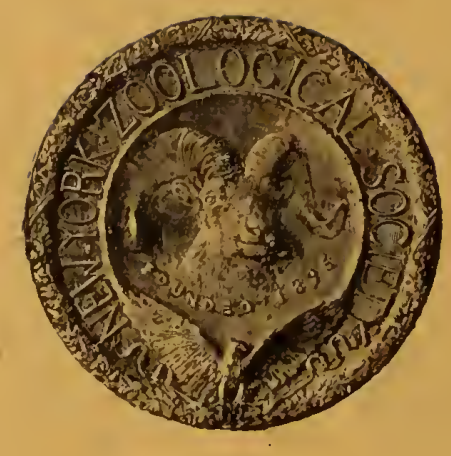

